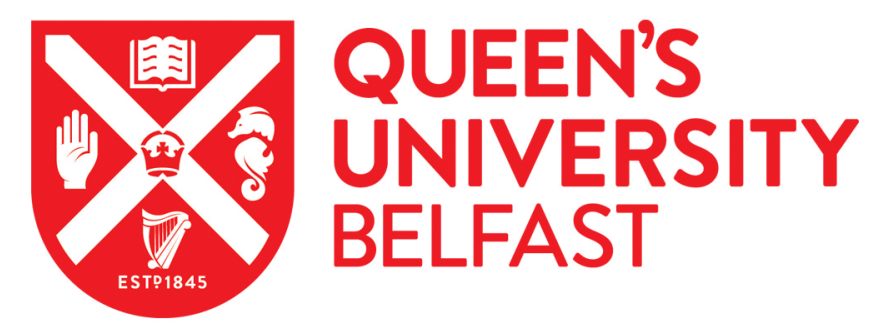

\title{
Extended-culture and culture-independent molecular analysis of the airway microbiota in cystic fibrosis following CFTR modulation with ivacaftor
}

Einarsson, G. G., Ronan, N. J., Mooney, D., McGettigan, C., Mullane, D., NiChroinin, M., Shanahan, F., Murphy, D. M., McCarthy, M., McCarthy, Y., Eustace, J. A., Gilpin, D. F., Elborn, J. S., Plant, B. J., \& Tunney, M. M. (2021). Extended-culture and culture-independent molecular analysis of the airway microbiota in cystic fibrosis following CFTR modulation with ivacaftor. Journal of cystic fibrosis : official journal of the European Cystic Fibrosis Society. https://doi.org/10.1016/j.jcf.2020.12.023

Published in:

Journal of cystic fibrosis : official journal of the European Cystic Fibrosis Society

Document Version:

Peer reviewed version

Queen's University Belfast - Research Portal:

Link to publication record in Queen's University Belfast Research Portal

Publisher rights

Copyright 2021 European Cystic Fibrosis Society. Published by Elsevier B.V.

This work is made available online in accordance with the publisher's policies. Please refer to any applicable terms of use of the publisher.

\section{General rights}

Copyright for the publications made accessible via the Queen's University Belfast Research Portal is retained by the author(s) and / or other copyright owners and it is a condition of accessing these publications that users recognise and abide by the legal requirements associated with these rights.

\section{Take down policy}

The Research Portal is Queen's institutional repository that provides access to Queen's research output. Every effort has been made to ensure that content in the Research Portal does not infringe any person's rights, or applicable UK laws. If you discover content in the Research Portal that you believe breaches copyright or violates any law, please contact openaccess@qub.ac.uk. 
1 Extended-culture and culture-independent molecular analysis of the airway

2 microbiota in cystic fibrosis following CFTR modulation with ivacaftor.

3

4

5

6

7

Gisli G. Einarsson a, b, 1, ${ }^{*}$, Nicola J. Ronan d, e, 1, Denver Mooney a, b, Clodagh McGettigan a, c, David Mullane ${ }^{d}$, Muireann NiChroinin ${ }^{d}$, Fergus Shanahan ${ }^{f}$, Desmond M. Murphy ${ }^{d, e}$, Mairead McCarthy ${ }^{d}, Y^{\prime}$ vonne McCarthy ${ }^{d}$, Joseph A. Eustace ${ }^{e}$, Deirdre F. Gilpin a, c, J Stuart Elborn a, b, 2 , Barry J. Plant ${ }^{d, ~ e, ~ f, ~ 2, ~ M i c h a e l ~ M . ~ T u n n e y ~ a, ~ c, ~} 2$

a Halo Research Group, Queen's University Belfast, Belfast, UK.

${ }^{b}$ Wellcome-Wolfson Institute for Experimental Medicine. School of Medicine, Dentistry and Biomedical Sciences Queen's University Belfast, Belfast, UK

c School of Pharmacy, Queen's University Belfast, Belfast, UK.

${ }^{d}$ Cork Centre for Cystic Fibrosis, Cork University Hospital, University College Cork, Ireland.

e HRB Clinical Research Facility, University College Cork, Cork, Ireland.

${ }^{f}$ Department of Medicine, Cork University Hospital, Wilton, Cork, Ireland.

* Corresponding author: Gisli G Einarsson (g.einarsson@qub.ac.uk)

${ }^{1}$ GGE and NJR are joint first authors on this paper.

2 JSE, BJP and MMT are joint senior authors on this paper.

Word Count: 2944/3000 
Background: Treatment with Ivacaftor provides a significant clinical benefit in people with cystic fibrosis (PWCF) with the class III G551D-CFTR mutation. This study determined the effect of CFTR modulation with ivacaftor on the lung microbiota in PWCF.

Methods: Using both extended-culture and culture-independent molecular methods, we analysed the lower airway microbiota of 14 PWCF, prior to commencing ivacaftor treatment and at the last available visit within the following year. We determined total bacterial and Pseudomonas aeruginosa densities by both culture and qPCR, assessed ecological parameters and community structure and compared these with biomarkers of inflammation and clinical outcomes.

Results: Significant improvement in $\mathrm{FEV}_{1}, \mathrm{BMI}$, sweat chloride and levels of circulating inflammatory biomarkers were observed POST-ivacaftor treatment. 
51 CF lung disease. Furthermore, a significant correlation was observed between 52 richness and diversity and levels of circulating inflammatory markers.

53 


\section{INTRODUCTION}

55 In people with CF (PWCF), CFTR dysfunction in the lower airways results in dehydrated airway secretions and a severe impairment of mucociliary clearance, which results in a cycle of chronic infection and inflammation. Ivacaftor, a first-in-class molecule, enhances CFTR function in class III (gating) and class IV (conductance) mutations $[1,2]$ by increasing the probability of CFTR-channel opening. The G551DCFTR mutation displays a severe phenotype and is the most commonly detected class III mutation with a worldwide prevalence of $4-5 \%$ [3]. However, significant regional variation exists with the prevalence highest in Ireland with the Cork CF Centre at around $23 \%$ [4]. Studies focusing on the efficacy of ivacaftor have demonstrated significant improvement in lung function $\left(F E V_{1}\right)$, weight gain, improved respiratory symptoms, reduction in sweat chloride levels and a decrease in frequency of pulmonary exacerbations $[1,4]$. The physiochemical nature of the environment in the lungs of PWCF may act as a strong selective force affecting microbiota composition in the lower airways [5]. Ivacaftor increases transportation of chloride ions across the cell membrane resulting in rehydration of the airway surface layer. These changes in the airway microenvironment also alter $\mathrm{pH}$ and mucus viscosity and may also have an effect on the resident microbiota. Indeed, a number of studies have reported changes in the lung microbiota following treatment with ivacaftor [6-8]. Furthermore, it has been suggested that ivacaftor may exhibit antimicrobial properties with Payne and colleagues demonstrating activity against Gram-positive microorganisms [9].

Given the relatively high allele frequency of G551D-CFTR in our centre, we previously reported the largest single centre study focusing on ivacaftor treatment in this group of PWCF [4]. In the current study, we hypothesised that, in addition to improvement in 
clinical status in PWCF with at least one copy of the G551D-CFTR mutation, treatment with ivacaftor results in significant changes in lower airway microbial community composition and structure and inflammation.

\section{MATERIALS AND METHODS}

\section{Ethics statement and patient recruitment}

Ethical approval was obtained from the Clinical Research Ethics Committee of the Cork Teaching Hospitals. PWCF ( $n=14$; median age, 26 years; range: 13-39 years) with at least one copy of the G551D-CFTR mutation, attending the Cork Cystic Fibrosis centre from March to December 2013, were followed prospectively, for a mean period of 12 months. This cohort represented a subset of PWCF from our previously published study that were able to provide sufficient sputum at baseline (prior to commencing ivacaftor treatment; [PRE]) and at the last available time-point up to 12 months (post-treatment; [POST]) for microbiota analysis. Clinical data including spirometry, performed in keeping with ERS/ATS guidelines, sweat chloride, BMI and number of courses of IV antibiotics was recorded prospectively before commencing ivacaftor and in the year after treatment.

\section{Sample collection and processing}

Expectorated sputum samples were collected during the PRE-treatment visit for the initiation of ivacaftor treatment and at the last POST-treatment visit (i.e. at 9 or 12 months). All 14 patients provided sufficient sputum to allow culture-independent molecular analysis with a further 10 patients providing sufficient sputum to also allow processing by extended-quantitative bacterial culture. Sputum samples were stored at 
$-80^{\circ} \mathrm{C}$ and shipped on dry ice to Queen's University Belfast where they were stored at $-80^{\circ} \mathrm{C}$ until processing. Blood samples were also collected from all participants at each clinic visit. A multiplex enzyme linked immunosorbent assay (MesoScale Discovery platform) was used to quantify inflammatory biomarkers in blood: interleukin 6 and 8 (IL-6; IL-8), Tumour Necrosis Factor a (TNF- $\alpha$ ), Interferon-y (IFN-y)] and C-reactive protein (CRP) (Meso Scale Diagnostics, USA).

\section{Extended bacterial culture}

Extended-quantitative bacterial culture of sputum samples and detection and identification of isolated bacteria were performed as previously described [10,11]. For further description of detailed methods, see Supplementary File S1.

\section{Molecular detection}

Genomic DNA (gDNA) was extracted from 200mg sputum aliquots, along with appropriate controls, by treatment with Sputolysin $\Theta$, mechanical disruption and processing on an automated nucleic acid purification platform (Roche MagNA Pure).

\section{i. qPCR quantification of total bacterial and $P$. aeruginosa (PA) density}

$P$. aeruginosa and total bacterial density was determined by $\mathrm{qPCR}$ using the LightCycler®480 instrument (Roche, $\mathrm{CH}$ ) using the Probes Master kit. Total bacterial load was determined using a primer/probe targeting the bacterial 16S rRNA markergene [12], with $P$. aeruginosa load determined using a primer/probe set targeting the oprL gene [13]. For further description of detailed methods, see Supplementary File S1. 


\section{ii. Illumina MiSeq sequencing}

124

125

126

127

Molecular characterization of the airway microbiota was performed using the Illumina MiSeq NGS platform (Illumina, USA) targeting the 16S rRNA marker gene as described below. For sequencing, we targeted the V4 region of the bacterial 16S rRNA marker-gene in a two-step library preparation, applying modified universal primers as previously described by Lundberg et al. [14]. In brief, bead-cleaned nucleotide libraries in equimolar concentrations of amplicons (approx. 452 base pairs in size) were sequenced on an Illumina MiSeq sequencing platform using the version-3 (V3) pairedend 600 cycle kit. Following completion of the MiSeq run, the raw sequence data was deposited to the European Nucleotide Archive (ENA) (Study Accession: PRJEB37510). Downstream analysis of raw sequence read, OTU calling (operational taxonomic units) and data analysis was performed in QIIME 1.9.1 (Quantitative Insights Into Microbial Ecology) [15] and R version 3.4.2. (https://www.r-project.org/). Further details regarding sample handling, sequence library preparation, quantification, MiSeq marker-gene sequencing, handling and removal of potential background contamination from technical sequence controls and downstream analysis are provided in Supplementary File S1. The metadata mapping file for MiSeq processing and analysis is provided in Table S1.

\section{Statistical analysis and ecological community measurements}

Assessment of the data demonstrated that for most of the included variables, the data did not conform to normal normality (Shapiro-Wilks normality test; $p \leq 0.05$ ). Hence, nonparametric analyses were performed, which included the Mann-Whitney $U$ test, Wilcoxon signed-rank test, Spearman's ( $r$ ) ranked correlation and Pearson ( $r$ ) correlation test for count based and clinically relevant data where appropriate. The 
analysis of microbial community based (extended culture and molecular based data) and clinical data was conducted in the R environment (https://www.r-project.org). P $<0.05$ was accepted as statistically significant. Further details regarding specific packages and analysis are provided in Supplementary File S1.

\section{RESULTS}

Patient demographic data are summarised in Table 1 with Table S2 summarising total antibiotic usage in the year prior to or after ivacaftor treatment for this cohort. A significant reduction in sweat chloride concentration $(p=0.0001)$ and a significant increase in lung function ( $F E V_{1} \%$ predicted; $p=0.001$ ) was observed in the year following ivacaftor treatment (Fig. S1).

\section{Extended bacterial culture}

Bacteria were cultured in high numbers from all sputum samples collected PRE- (up to $2.08 \times 10^{8} \mathrm{CFU} / \mathrm{g}$ of sputum) and POST-treatment (up to $1.25 \times 10^{8} \mathrm{CFU} / \mathrm{g}$ of sputum) with ivacaftor. There was no significant difference in the total bacterial density cultured from PRE- $\left(1.32 \times 10^{7}\left[3.00 \times 10^{4}\right.\right.$ to $\left.8.60 \times 10^{7}\right] \mathrm{CFU} / \mathrm{g}$ of sputum; median [range] $)$ or POST-treatment $\left(8.52 \times 10^{6}\left[3.60 \times 10^{5}\right.\right.$ to $\left.5.60 \times 10^{7}\right] \mathrm{CFU} / \mathrm{g}$ of sputum; median [range]) samples (Fig. 1A). Aerobic bacteria were cultured in high abundance from all PRE- (up to $2.07 \times 10^{8} \mathrm{CFU} / \mathrm{g}$ of sputum) and POST-treatment (up to $1.08 \mathrm{x}$ $10^{8} \mathrm{CFU} / \mathrm{g}$ of sputum) samples. There was no significant difference in the median values of total aerobic bacterial density from PRE- $\left(1.23 \times 10^{7}\left[3.00 \times 10^{4}\right.\right.$ to $8.60 \times$ $\left.10^{7}\right] \mathrm{CFU} / \mathrm{g}$ of sputum; median [range]) versus POST-treatment $\left(7.49 \times 10^{6}\left[3.60 \times 10^{5}\right.\right.$ to $4.79 \times 10^{7} \mathrm{CFU} / \mathrm{g}$ of sputum; median [range]) samples (Fig. 1B). Anaerobic bacteria were cultured from 5/10 PRE- (up to $1.40 \times 10^{6} \mathrm{CFU} / \mathrm{g}$ of sputum) and from all 10 
170 POST-treatment samples (up to $1.71 \times 10^{7} \mathrm{CFU} / \mathrm{g}$ of sputum). The total anaerobic

171 bacterial density PRE-treatment $\left(4.31 \times 10^{4}\left[0.0\right.\right.$ to $\left.2.39 \times 10^{6}\right] \mathrm{CFU} / \mathrm{g}$ of sputum; median [range]) was significantly lower than POST-treatment $\left(3.50 \times 10^{6}\left[9.26 \times 10^{3}\right.\right.$ to $2.96 \times 10^{7}$ ] CFU/g of sputum; median [range]) $(p=0.024$, Fig. $1 \mathrm{C})$. In total, we cultured 54 different bacterial taxa with no single taxa demonstrating significant difference PRE- and POST-treatment. All 6 patients who were $P$. aeruginosa positive by extended-culture pre-treatment were also $P$. aeruginosa positive POST-treatment with no significant difference in density. Further detailed information regarding total bacterial counts (CFU/g sputum [Log10]) and detected taxa are shown in Table S3. Significant differences were detected between PRE- and POST-treatment samples for both taxonomic richness and community diversity $\left(p=1.590 \times 10^{-4}\right.$ and $p=0.003$, respectively) (Fig. 1D and 1F, respectively).

\section{qPCR quantification of total bacterial and $P$. aeruginosa density}

No significant difference in fold change was observed for either total bacterial $16 \mathrm{~S}$ rRNA copy number $\left[6.30 \times 10^{8}\right.$ (PRE) and $4.14 \times 10^{8}$ (POST)] or $P$. aeruginosa density for opr copy number $\left[1.65 \times 10^{7}\right.$ (PRE) and $1.79 \times 10^{7}$ (POST)] following ivacaftor therapy (Table S1). We observed significant concurrence between $P$. aeruginosa TVC's (extended-culture) and oprL qPCR values for $P$. aeruginosa (Pearson productmoment correlation coefficient $r=0.56 ; R^{2}=0.301 ; p=0.007$; Bonferroni adjusted for multiple comparisons) (Fig. S2A). Furthermore, there was excellent agreement between the relative abundance of Pseudomonas spp. from Illumina MiSeq 16S rRNA marker-gene sequencing and opr qPCR values for $P$. aeruginosa (Pearson productmoment correlation coefficient $r=0.88 ; R^{2}=0.775 ; p=3.91^{*} 10^{-10}$; Bonferroni adjusted for multiple comparisons) (Fig. S2B). 


\section{Illumina MiSeq sequencing}

196

197

198

Following quality filtering and pre-processing of the paired-end sequence reads, each sample was normalised to 58,391 reads. In total, we detected 179 different taxa in the paired samples (PRE-ivacaftor [n=123]; POST-ivacaftor treatment $[n=160])$. Furthermore, a limited number of taxa (26/179) accounted for $99 \%$ of the total sequence read number in our cohort.

At the phylum level, the mean relative abundance of Proteobacteria was reduced by 22\% POST-treatment, while mean relative abundance of Firmicutes, Bacteriodetes, Actinobacteria and Fusobacteria increased by $12 \%, 13 \%, 57 \%$ and $500 \%$, respectively (Fig. 2A). At genera level, there was a significant change in community composition following treatment in samples from 9/14 PWCF, with only two of these individuals receiving IV antibiotics in the previous 8 weeks. In 5/14 PWCF, community composition remained relatively stable following treatment with only marginal changes in the relative abundance of the dominant genera (Fig. 2B); none of these 5 patients received IV antibiotics in the previous 8 weeks.

Comparison of taxonomic richness demonstrated a significant increase in observed taxa richness POST-treatment (Fig. 3A; $p=0.031$, Mann-Whitney test). Community diversity (Shannon-Wiener index [H']), although trending towards a higher diversity in the POST-treatment samples, did not show a significant difference between visits (Fig. 3B, $p=0.069$; Mann-Whitney test). Community evenness $\left(e^{H / S}\right)$ and dominance (D) were similar PRE- and POST-treatment $(p=0.085$ and $p=0.094$, respectively; MannWhitney test) (Fig. 3C and 3D, respectively). 
217 We observed a high degree of variation in the microbiota between patients (Fig. 2B). Inter- similarities/differences, based on $\beta$-diversity computed with the Bray-Curtis dissimilarity measures, demonstrated a significant difference between individual patients ( $R^{2}=0.70 ; p=0.006$; sample ADONIS; 9999 permutations). In contrast, analysis between PRE- and POST-treatment samples was not shown to be statistically significant ( $R^{2}=0.01 ; p=0.653$; PERMANOVA; 999 permutations) (Fig. S3A and S3B).

Communities dominated by a high relative abundance of members of Pseudomonas spp. were associated with lower taxonomic richness and diversity (Fig. S4 A-C), while communities with relatively higher abundance of members of Streptococcus spp. were associated with both higher taxonomic richness and diversity (Fig. S4 A-B and D). There was a general change in the direction of community composition following ivacaftor treatment from communities dominated by Pseudomonas spp., Stenotrophomonas spp. (classified as a "family of unclassified Xanthomonadaceae") and Staphylococcus spp. PRE-treatment towards communities with a higher relative abundance of Streptococcus spp. POST-treatment (Fig. S4 G, C, E and F, respectively).

\section{Lower Airway Microbiota and Host Inflammation}

For exploratory analysis, calculated the relationship between taxonomic richness and community diversity with the main markers of inflammation (adjusted for repeated measures). Circulating IL-6 and IL-8, blood CRP and TNF- $\alpha$ levels showed a significant inverse relationship with change in community richness (Fig. S5 A-D) ( $r=-$ $0.472[p=0.013] ; r=-0.472 \quad[p=0.013] ; r=-0.434 \quad[p=0.024] ; r=-0.445 \quad[p=0.020]$, respectively). There was also a significant inverse correlation between IL-8 ( $r=-0.412$; $p=0.033)$, TNF- $\alpha(r=-0.567 ; p=0.002)$ and community diversity; however, IL-6 ( $r=-$ 
$0.262 ; p=0.187)$ and $C R P(r=-0.150 ; p=0.455)$, did not show significant correlation with levels of community diversity (Fig. S5 E-H). No correlation was observed between ecological indices (taxonomic richness and community diversity) and IFN-Y ( $r=-0.205$ $[p=0.304] ; r=-0.131[p=0.514])$, respectively.

\section{DISCUSSION}

This is the first study to simultaneously use extended quantitative culture and cultureindependent methods to assess changes in microbial community composition following ivacaftor treatment. Extended culture detected a high number of both aerobic and strict anaerobic bacteria prior to commencing and POST-ivacaftor treatment, with total anaerobic bacterial numbers, community richness and diversity significantly higher following treatment. Culture-independent analysis did not demonstrate a significant effect on airway microbial community composition following ivacaftor treatment, despite significant changes being observed within individual patients. In general, where such changes occurred, the shift was from communities with a higher proportion of Pseudomonas spp., Stenotrophomonas spp. and Staphylococcus spp. towards communities with a higher proportion of Streptococcus spp. Following treatment, community structures displayed an increase in taxonomic richness as well as a trend towards higher community diversity. Furthermore, we observed a significant inverse relationship between community richness and markers of inflammation in blood. This shift is in the direction of a bacterial ecology associated with less severe CF lung disease [16].

A key finding from the current study is that, despite significant improvements in many of the clinically relevant parameters, ivacaftor treatment did not result in eradication of $P$. aeruginosa from the airways. This contrasts with the findings of Heltshe and colleagues who reported a significant reduction in $P$. aeruginosa culture positivity one 
year after initiation of ivacaftor therapy [17]. However, the results of this earlier study may have been skewed by the inclusion of patients defined as having intermittent $P$. aeruginosa infection prior to initiation of ivacaftor therapy. Our findings are similar to those of Hisert et al. who followed PWCF longitudinally for up to 3 years and reported that none of the 8 patients chronically colonised with $P$. aeruginosa eradicated their infecting strain [18]. We did not demonstrate, by either culture or qPCR, a significant difference in $P$. aeruginosa density in PRE- and POST-treatment samples. In contrast, Hisert et al., who performed more frequent sample analysis, reported a significant reduction in $P$. aeruginosa density in the first week of treatment which was maintained for approximately 7 months (day 210 ). However, $P$. aeruginosa density increased in 6/7 patients over the remaining study period [18]. As our POST-treatment samples were collected at either 9 or 12 months, it is likely that any initial reduction in $P$. aeruginosa density, if present, would have been reversed by 9 or 12 months and therefore not detected.

Of interest, Peleg and co-workers demonstrated that, although significant changes in microbial community composition occurred following ivacaftor treatment, they were primarily as a result of concurrent antibiotic exposure. PWCF that did not receive intravenous antibiotic treatment only demonstrated modest changes in their microbiota [19]. However, only 2/14 PWCF in our study that displayed a significant shift in microbial community composition had received a course of intravenous antibiotics in the eight weeks preceding collection of the POST-treatment sample. Changes in the lung environment, such as modulation in $\mathrm{pH}$ levels of the airway surface liquid (ASL) can have a significant effect on its viscosity [20], stabilisation of mucin binding and local host defence mechanisms [21]. This suggests that changes in the airway environment could play a significant role in shaping community composition as well as 
modulating the virulence potential of a number of the main pathogenic taxa as these were seldom eliminated from the community following ivacaftor treatment $[22,23]$.

293

294

295

No direct association between individual bacterial taxa, community diversity or taxonomic richness and lung function were detected. However, increased taxonomic richness was associated with decreased systemic and airway inflammation. This suggests that an increase in bacterial diversity, richness and abundance of anaerobic bacteria may be linked to improvements in clinical status in PWCF receiving ivacaftor therapy via downregulation of the host's inflammatory response.

The current study has a number of limitations. As this is a single centre study, inferring the results to findings elsewhere may be difficult. However, the current study is the largest single centre study reported to date. Importantly, we used both extendedculture and culture-independent methods to examine the effect of ivacaftor on bacterial communities present in sputum from PWCF in a region that shows the highest prevalence of the G551D-CFTR mutation in the world. Our study is also observational in nature and did not include a matched control group of individuals that did not receive ivacaftor. However, the benefits of ivacaftor relative to placebo have been well demonstrated in existing trials, and the observed clinical improvements in the current study are comparable to those previously reported.

\section{CONCLUSIONS}

Variation in microbial community composition and the prevalence of pathogenic taxa were highly individual without an overall significant change in either following ivacaftor treatment. Changes in the airway environment and circulating inflammatory cytokine 
levels as a consequence of ivacaftor treatment, may result in an indirect effect on the local microbiota and modulate the virulence of pathogenic members of the community.

Acknowledgements:

Contribution: NJR, FS, JAE, MMM and BJP contributed to study design. GGE, NJR,

DM, MT, DM, CMcG, MC, GOC, DMM, OJOC, CAS, MMT, JAE, MMM, JSE, BJP and MMT contributed to data acquisition, analysis and interpretation. All authors contributed to drafting the work and final approval.

CFMATTERS, Grant agreement 603038.

Competing interests: None declared.

Ethics approval: Ethical approval was obtained from the Clinical Research Ethics Committee of the Cork Teaching Hospitals.

Data sharing statement Data deposition: Sequencing data are deposited in the European Nucleotide Archive database (Study Accession: PRJEB37510). Data submitted but unreleased to public until publication. 
341 [1] Ramsey BW, Davies J, McElvaney NG, Tullis E, Bell SC, Drevinek P, et al. A CFTR potentiator in

[2] Davies J, Sheridan H, Bell N, Cunningham S, Davis SD, Elborn JS, et al. Assessment of clinical response to ivacaftor with lung clearance index in cystic fibrosis patients with a G551D-CFTR mutation and preserved spirometry: a randomised controlled trial. Lancet Respir Med. 2013;1:630-8.

[3] Cutting GR. Cystic fibrosis genetics: from molecular understanding to clinical application. Nat Rev Genet. 2015;16:45-56. Epub 2014 Nov 18 doi:10.1038/nrg3849.

[4] Ronan NJ, Einarsson GG, Twomey M, Mooney D, Mullane D, NiChroinin M, et al. CORK Study in Cystic Fibrosis: Sustained Improvements in Ultra-Low-Dose Chest CT Scores After CFTR Modulation With Ivacaftor. Chest. 2018;153:395-403.

[5] Quinn RA, Lim YW, Maughan H, Conrad D, Rohwer F, Whiteson KL. Biogeochemical Forces Shape the Composition and Physiology of Polymicrobial Communities in the Cystic Fibrosis Lung. mBio. 2014;5:. doi:10.1128/mBio.00956-13.

[6] Rowe SM, Heltshe SL, Gonska T, Donaldson SH, Borowitz D, Gelfond D, et al. Clinical Mechanism of the Cystic Fibrosis Transmembrane Conductance Regulator Potentiator Ivacaftor in G551D-mediated Cystic Fibrosis. Am J Respir Crit Care Med. 2014;190:175-84. Epub 2014 Jul 15 doi:10.1164/rccm.201404-07030C.

[7] Bernarde C, Keravec M, Mounier J, Gouriou S, Rault G, Ferec C, et al. Impact of the CFTR-potentiator ivacaftor on airway microbiota in cystic fibrosis patients carrying a G551D mutation. PLoS One. 2015;10:e0124124.

[8] Reznikov LR, Abou Alaiwa MH, Dohrn CL, Gansemer ND, Diekema DJ, Stoltz DA, et al. Antibacterial properties of the CFTR potentiator ivacaftor. J Cyst Fibros. 2014;13:515-9.

[9] Payne JE, Dubois AV, Ingram RJ, Weldon S, Taggart CC, Elborn JS, et al. Activity of innate antimicrobial peptides and ivacaftor against clinical cystic fibrosis respiratory pathogens. Int J Antimicrob Agents. 2017;50:427-35.

[10] Einarsson GG, Comer DM, Mcllreavey L, Parkhill J, Ennis M, Tunney MM, et al. Community dynamics and the lower airway microbiota in stable chronic obstructive pulmonary disease, smokers and healthy non-smokers. Thorax. 2016;71:795-803.

[11] Sherrard L, Einarsson GG, Johnston E, O'Neill K, Mcllreavey L, McGrath SJ, et al. Assessment of stability and fluctuations of cultured lower airway bacterial communities in people with cystic fibrosis. J Cyst Fibros. 2019;18:808-16.

[12] Nadkarni MA, Martin FE, Jacques NA, Hunter N. Determination of bacterial load by real-time PCR using a broad-range (universal) probe and primers set. Microbiology. 2002;148:257-66.

[13] Deschaght P, Schelstraete P, Lopes dos Santos Santiago G, Van Simaey L, Haerynck F, Van daele $\mathrm{S}$, et al. Comparison of culture and qPCR for the detection of Pseudomonas aeruginosa in not chronically infected cystic fibrosis patients. BMC Microbiol. 2010;10:245.:10.1186/471-2180-10-245. [14] Lundberg DS, Yourstone S, Mieczkowski P, Jones CD, Dangl JL. Practical innovations for highthroughput amplicon sequencing. Nat Methods. 2013;10:999-1002.

[15] Caporaso JG, Kuczynski J, Stombaugh J, Bittinger K, Bushman FD, Costello EK, et al. QIIME allows analysis of high-throughput community sequencing data. Nat Methods. 2010;7:335-6.

[16] Muhlebach MS, Hatch JE, Einarsson GG, McGrath SJ, Gilipin DF, Lavelle G, et al. Anaerobic bacteria cultured from CF airways correlate to milder disease-a multisite study. Eur Respir J. 2018;52:. Epub 2018 Jul 11 doi:10.1183/13993003.00242-2018.

[17] Heltshe SL, Mayer-Hamblett N, Burns JL, Khan U, Baines A, Ramsey BW, et al. Pseudomonas aeruginosa in cystic fibrosis patients with G551D-CFTR treated with ivacaftor. Clin Infect Dis. 2015;60:703-12. 
[18] Hisert KB, Heltshe SL, Pope C, Jorth P, Wu X, Edwards RM, et al. Restoring Cystic Fibrosis Transmembrane Conductance Regulator Function Reduces Airway Bacteria and Inflammation in People with Cystic Fibrosis and Chronic Lung Infections. Am J Respir Crit Care Med. 2017;195:1617-28. [19] Peleg AY, Choo JM, Langan KM, Edgeworth D, Keating D, Wilson J, et al. Antibiotic exposure and interpersonal variance mask the effect of ivacaftor on respiratory microbiota composition. J Cyst Fibros. 2018;17:50-6. doi: 10.1016/j.jcf.2017.08.002. Epub Oct 15.

[20] Tang XX, Ostedgaard LS, Hoegger MJ, Moninger TO, Karp PH, McMenimen JD, et al. Acidic pH increases airway surface liquid viscosity in cystic fibrosis. J Clin Invest. 2016;126:879-91. doi: 10.1172/JCl83922. Epub 2016 Jan 25.

[21] Berkebile AR, McCray PB, Jr. Effects of airway surface liquid pH on host defense in cystic fibrosis. Int J Biochem Cell Biol. 2014;52:124-9.:10.1016/j.biocel.2014.02.009. Epub Feb 19. [22] Pezzulo AA, Tang XX, Hoegger MJ, Alaiwa MHA, Ramachandran S, Moninger TO, et al. Reduced airway surface $\mathrm{pH}$ impairs bacterial killing in the porcine cystic fibrosis lung. Nature. 2012;487:109.

400 [23] Shah VS, Meyerholz DK, Tang XX, Reznikov L, Alaiwa MA, Ernst SE, et al. Airway acidification

401 initiates host defense abnormalities in cystic fibrosis mice. Science. 2016;351:503-7.

402

403

404

405

406

407

408

409

410

411

412

413 
415 Table 1. Patient demographics.

\begin{tabular}{|c|c|c|c|}
\hline Number of PWCF & 14 & & \\
\hline $\begin{array}{l}\text { Age at Baseline (years; } \\
\text { median; range) }\end{array}$ & $25.3(26.5 ; 13-37)$ & & \\
\hline \multirow[t]{2}{*}{ Gender (female/male) } & $5 / 9$ & & \\
\hline & PRE & POST & p-value \\
\hline BMI & $20.90(16.20-24.80)$ & $22.18(17.30-26.00)$ & 0.006 \\
\hline IL-6 (Log10; mean [range]) & $2.81(2.39-3.76)$ & $2.68(2.43-3.25)$ & 0.009 \\
\hline IL-8 (Log10; mean [range]) & $3.36(2.90-3.81)$ & $3.35(3.01-3.88)$ & 0.799 \\
\hline CRP (Log10; mean [range]) & $4.13(2.98-5.74)$ & $4.13(3.18-5.21)$ & 0.076 \\
\hline TNF- $\alpha$ (Log10; mean [range]) & $2.86(2.57-2.93)$ & $2.84(2.31-3.02)$ & 0.683 \\
\hline IFN-y (Log10; mean [range]) & $2.89(2.79-3.11)$ & $2.85(2.63-3.02)$ & 0.227 \\
\hline \multicolumn{4}{|l|}{ Genotype } \\
\hline \multicolumn{4}{|c|}{ G551D/F508del (12); G551D/G551D (1); G551D/R553x (1) } \\
\hline
\end{tabular}



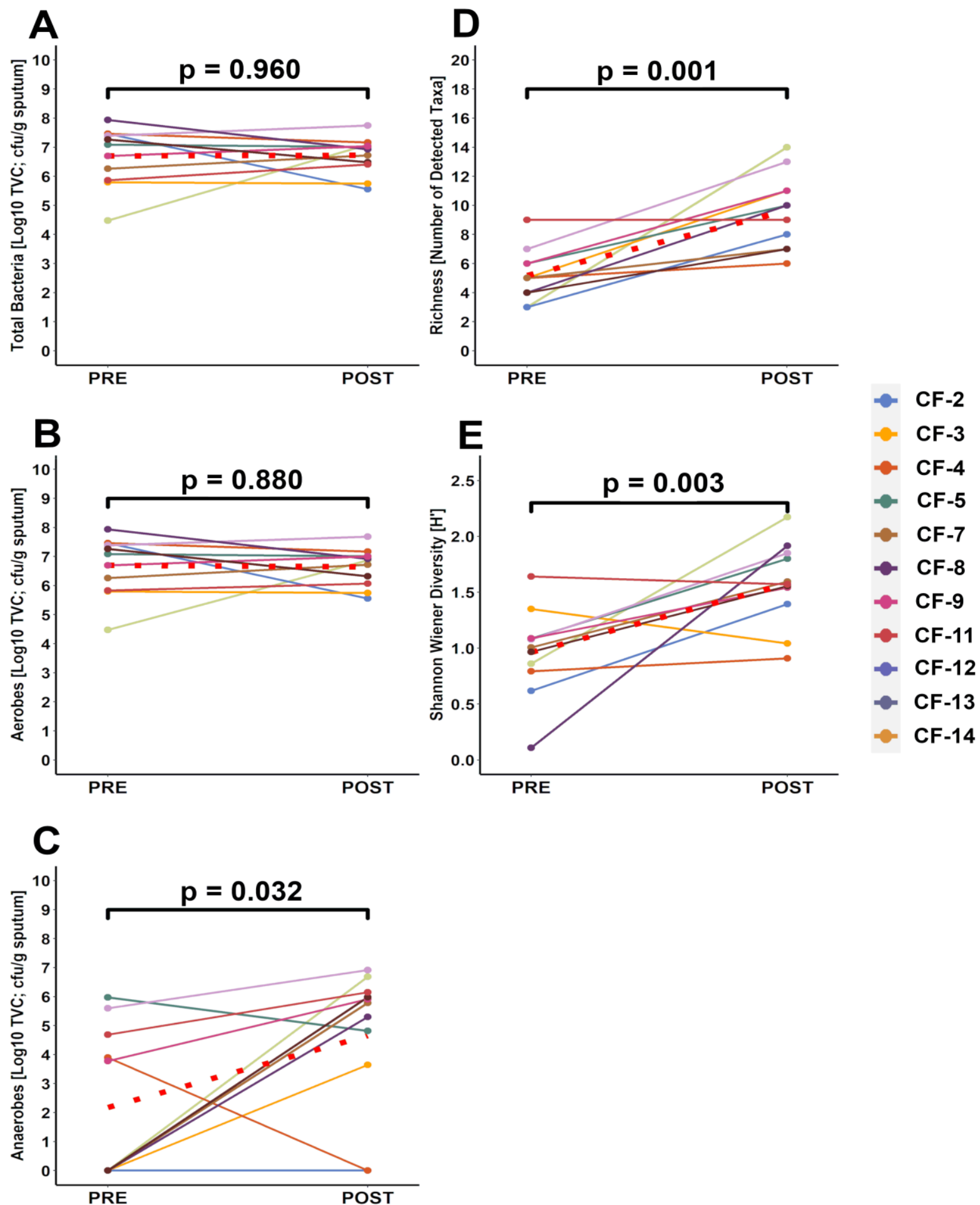

Fig 1. Comparison of sputum viable counts and ecological parameters by extended-bacterial culture in sputum samples from PWCF PRE- and POST-treatment with ivacaftor. (A) total bacterial load $(B)$ total bacterial load for aerobic bacteria $(C)$ total bacterial load for anaerobic bacteria (D) taxonomic richness and (E) community diversity (Shannon Wiener Index [H']). Red dotted line demonstrates the change in mean values. $\mathrm{P}<0.05$ denotes statistical significance. 
A

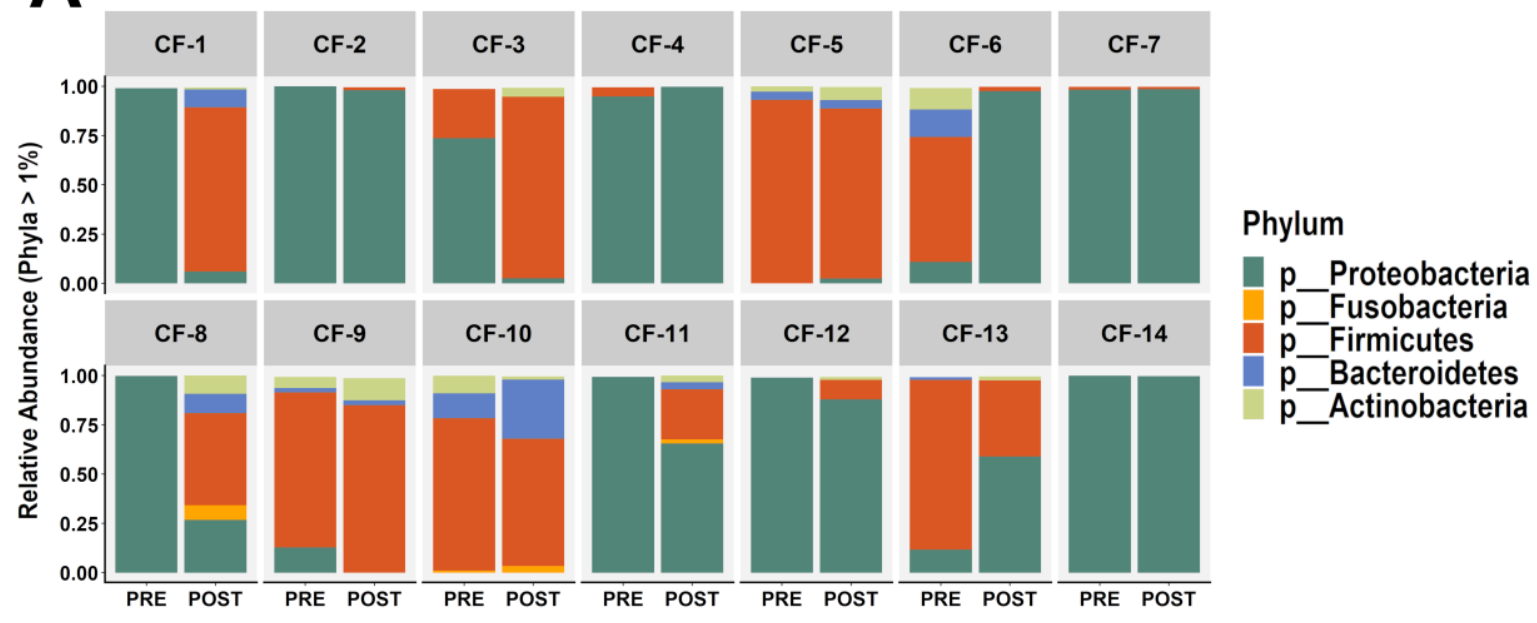

B

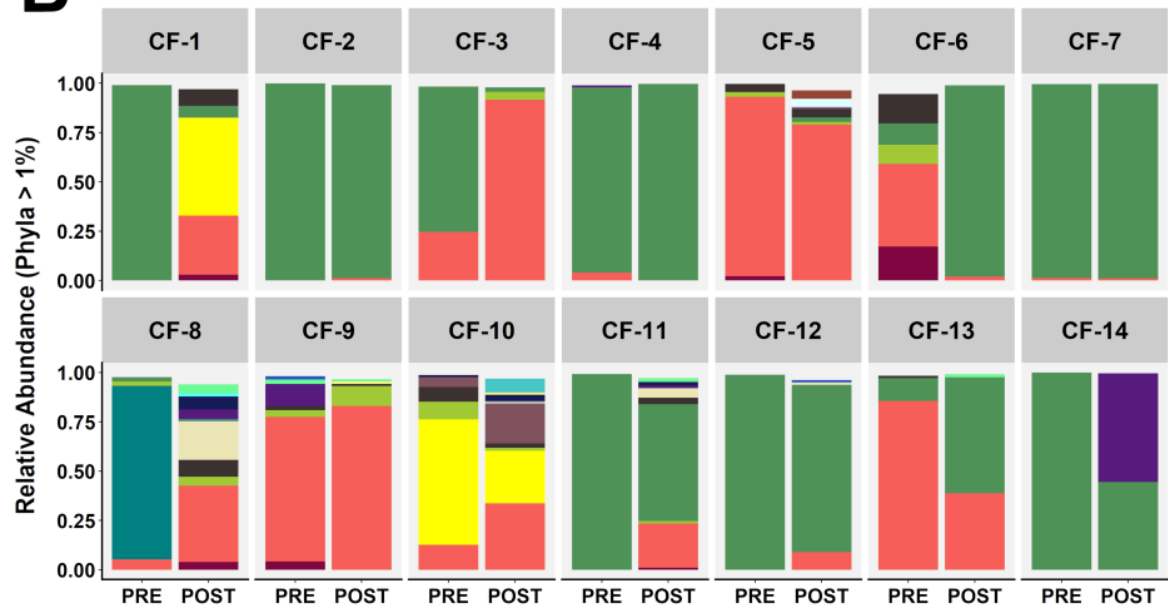

Genus

g_-Veillonella

g_-Stenotrophomonas

g_-Staphylococcus

g_ Rothia

g_Pseudomonas

g_Prevotella

g__Porphyromonas

g__Oribacterium

g_-Neisseria

g_-Megasphaera

g_Leptotrichia

g_Lactobacillus

g-Haemophilus

g_Fusobacterium

g_Capnocytophaga

g__ulleidia

g-Bifidobacterium

g_-Actinomyces

g__[Prevotella]

426 Fig 2. Mean relative abundance (\%) of $(A)$ top 5 phyla and $(B)$ all genera in sputum samples

427 from PWCF PRE- and POST-treatment with ivacaftor. Values shown depict percentage relative abundance $>1 \%$ of the total bacteria detected. 

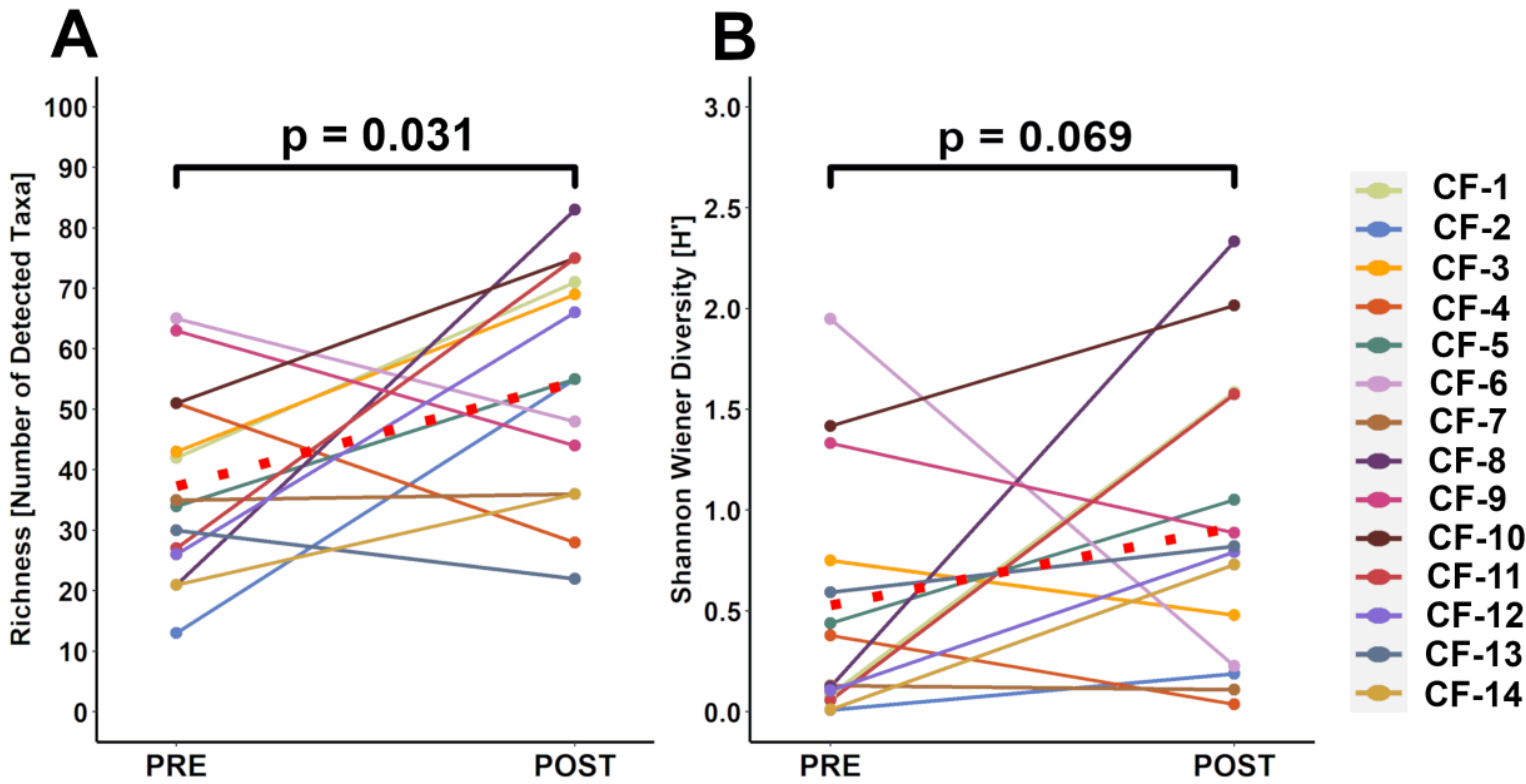

Fig 3. Comparison of ecological parameters by molecular based analysis in sputum samples from PWCF PRE- and POST-treatment with ivacaftor. (A) taxonomic richness (B) community diversity (Shannon Wiener Diversity $\left.\left[\mathrm{H}^{\prime}\right]\right)$. Red dotted line demonstrates the change in mean values. $\mathrm{P}<0.05$ denotes statistical significance. 
Extended-culture and culture-independent molecular analysis of the airway microbiota in cystic fibrosis following CFTR modulation with ivacaftor.

Gisli G. Einarsson a, b, 1, ${ }^{*}$, Nicola J. Ronan ${ }^{\text {d, e, } 1}$, Denver Mooney a, b, Clodagh McGettigan a, c, David Mullane ${ }^{d}$, Muireann NiChroinin ${ }^{d}$, Fergus Shanahan ${ }^{f}$, Desmond M. Murphy ${ }^{d, e}$, Mairead McCarthy ${ }^{d}$, Yvonne McCarthy ${ }^{d}$, Joseph A. Eustace ${ }^{e}$, Deirdre F. Gilpin ${ }^{a, c}$, J Stuart Elborn ${ }^{a, b}$,

${ }^{2}$, Barry J. Plant ${ }^{\mathrm{d}, \mathrm{e}, \mathrm{f}, 2}$, Michael M. Tunney ${ }^{\mathrm{a}, \mathrm{c}, 2}$

459

a Halo Research Group, Queen's University Belfast, Belfast, UK.

b Wellcome-Wolfson Institute for Experimental Medicine. School of Medicine, Dentistry and Biomedical Sciences Queen's University Belfast, Belfast, UK

‘School of Pharmacy, Queen's University Belfast, Belfast, UK.

${ }^{\mathrm{d}}$ Cork Centre for Cystic Fibrosis, Cork University Hospital, University College Cork, Ireland.

e HRB Clinical Research Facility, University College Cork, Cork, Ireland.

${ }^{\mathrm{f}}$ Department of Medicine, Cork University Hospital, Wilton, Cork, Ireland.

467

* Corresponding author: Gisli G Einarsson (g.einarsson@qub.ac.uk)

${ }^{1}$ GGE and NJR are joint first authors on this paper.

471

472

473

${ }^{2}$ JSE, BJP and MMT are joint senior authors on this paper.

Expectorated sputum samples were collected into a sterile specimen cup, snap frozen and immediately stored at $-80^{\circ} \mathrm{C}$ until being shipped on dry-ice to the Halo Research Group laboratory at Queen's University Belfast were samples were processed according to Standard Operating Procedures. Specimens were transferred to an anaerobic workstation (Don Whitley Scientific, UK) prior to loosening of the lid of the specimen cup. In the anaerobic cabinet, a sterile pipette was used to transfer $\sim 0.5$ gram of the sputum sample to a sterile $15 \mathrm{ml}$ centrifuge tube. The sputum samples were homogenized and liquefied by the addition of $10 \%$ Sputolysin 
481 (Calbiochem, USA) in a ratio of 1:1 (v/v). The sputum/sputolysin mixture was thoroughly mixed

482 by vortexing for 30 seconds, incubated for 15 minutes at $37^{\circ} \mathrm{C}$, under anaerobic conditions,

483 before being vortexed for a further 30 seconds. Next, the sputum/sputolysin mixture was 484 diluted 1:10 in $900 \mu$ of QSRS and serially diluted, 1:10, to a $10^{-5}$ dilution in QSRS in microtubes. An aliquot $(100 \mu \mathrm{l})$ of each dilution was inoculated onto anaerobic blood agar (ABA), kanamycin-vancomycin laked blood agar (KVLB) and blood chocolate agar (BCA) containing bacitracin and incubated aerobically, anaerobically (10\% hydrogen, $10 \%$ carbon dioxide and $80 \%$ nitrogen) or in $5 \% \mathrm{CO}_{2}$ at $37^{\circ} \mathrm{C}$ for $2-5$ days. The total viable count (colony forming units per gram of sputum) of all distinct colony morphologies was performed for enumeration of bacteria. Genomic DNA (gDNA) was extracted from bacteria that had been freshly grown on agar plates. For aerobes, DNA was isolated using a DNeasy Blood and Tissue kit (Qiagen, DE) as per manufacturer's instructions. For anaerobes, DNA was isolated using a ZR Fecal DNA MiniPrep kit (Zymo Research, USA) as per manufacturer's instructions. The final concentration of gDNA obtained was determined spectrophotometrically (Absorbance at 260/280nm).

496

To identify the genera of the cultured taxa, an initial amplification of the 16S rRNA markergene was performed using the 27F (5'-AGAGTTTGATCMTGGCTCAG-3') and 1492R (5'TACGGYTACCTTGTTACGACTT-3') primer pair [24] resulting in a near full-length 16S rRNA product. For each reaction, $1 \mu \mathrm{L}$ of genomic DNA template was added to the reaction mixture (25 $\mu \mathrm{L}$, final volume) containing $12.5 \mu \mathrm{L}$ of MyTaq ${ }^{\mathrm{TM}}$ Red $\times 2$ master-mix (Bioline, UK), $11 \mu \mathrm{L}$ of DEPC treated water (Ambion, USA) and $0.5 \mu \mathrm{L}$ of each primer (10 $\mu \mathrm{M}$ stock). The amplification step was performed on the Veriti 96-well thermal cycler (Applied Biosystems, USA) and included an initial denaturation step at $95^{\circ} \mathrm{C}$ for 3 minutes, followed by 30 cycles of denaturation at $95^{\circ} \mathrm{C}$ for 20 seconds, annealing at $50^{\circ} \mathrm{C}$ for 15 seconds, elongation at $72{ }^{\circ} \mathrm{C}$ for 60 seconds, and a final elongation step at $72{ }^{\circ} \mathrm{C}$ for 5 minutes. Following amplification, the resulting product was separated by electrophoresis on a 1.5\% agarose gel (Invitrogen, Life 
Technologies, USA) and visualised under short-wavelength UV light to ensure the appropriate amplification specificity of the 16S rRNA gene. For $16 \mathrm{~S}$ rRNA gene sequencing, an additional primer, 926R (5'-CCGTCAATTCCTTTRAGTTT-3), was used [25]. Resulting sequences were quality checked and the MUSCLE algorithm [26] was used to assemble overlapping amplicons into a single contig spanning near full length $16 \mathrm{~S}$ rRNA gene. Contigs were compared to the NCBI reference genome database (https://www.ncbi.nlm.nih.gov/refseq/) using the Blastn algorithm [27], and also to reference sequences contained within the Ribosomal Database Project (RDP) using the RDP Classifier algorithm [28] enabling relevant taxonomic classification of each cultured bacterium.

\section{Generation and processing of $16 \mathrm{~S}$ rRNA amplicon sequences for microbiome} analysis

Sputum samples extraction of gDNA was performed on the MagNA Pure 96 instrument (Roche Diagnostics Ltd., UK) as follows. A volume of $1.8 \mathrm{ml}$ of sterile Phosphate Buffered Saline (PBS) was added to the corresponding sample tube of pre-aliquoted Sputolysin stock to obtain a $10 \%$ Sputolysin solution. Library preparation for Illumina MiSeq sequencing of the 16S rRNA marker-gene was preformed as follows according to previously published protocol by Lundberg et al. [29]:

PCR 1: Pre-amplification of $16 \mathrm{~S}$ rRNA marker gene region is necessary for potentially low biomass template in order to carry enough tagged amplicon through to the final indexing-amplication steps. Perform PCR using 200 ng of gDNA from each sample. Using non-modified primers targeting positions 515F and 806R within the $\mathrm{V} 4$ region of the 16S rRNA marker gene prepare a mastermix solution [5 4 l 5x Phusion Hifi Buffer, $0.5 \mu \mathrm{l}(10 \mathrm{mM}) \mathrm{dNTP}, 1 \mu \mathrm{l}(10 \mu \mathrm{M}) \mathrm{V} 4$ primer mix; $0.25 \mu \mathrm{l}$ Phusion HS II polymerase and make to $25 \mu \mathrm{l}$ per reaction using DEPC water] and amplify using the following condition: $98^{\circ} \mathrm{C}$ for $30 \mathrm{sec}(\mathrm{x} 1) \rightarrow 98^{\circ} \mathrm{C}$ for $10 \mathrm{sec}+52^{\circ} \mathrm{C}$ for $30 \mathrm{sec}+72^{\circ} \mathrm{C}$ for $20 \mathrm{sec}(10$ cycles $)$ 
$\rightarrow 72^{\circ} \mathrm{C}$ for 5 min $\rightarrow$ hold at $4^{\circ} \mathrm{C}$ for $\infty$. Next clean-up the PCR products from PCR 1 using AxyPrep Mag PCR Clean-up kit as follows; vortex magnetic beads well before use to resuspend any magnetic beads that may have settled. Aliquot $15 \mu \mathrm{l}$ of Axygen beads to $10 \mu \mathrm{l}$ of PCR product into a sterile 96 well plate. Mix well by repeated pipetting and incubate at $\mathrm{R}^{\circ} \mathrm{T}$ for $5 \mathrm{~min}$. Place the reaction plate onto the IMAG separation device and wait until the liquid goes clear. Remove the clear liquid from the plate and discard. Next add $180 \mu \mathrm{l}$ of $70 \% \mathrm{EtOH}$ to each well of the reaction plate and incubate for $30 \mathrm{sec}$ at $\mathrm{R}^{\circ} \mathrm{T}$. Remove the $70 \% \mathrm{EtOH}$ from each well and discard. Repeat the previous step once. Air dry the beads at $\mathrm{R}^{\circ} \mathrm{T}$ for no more than 5 min and be careful not to over dry the magnetic beads as this will cause the beads to crack and lead to decreased elution efficiency. Ensure that all the ethanol has been removed from each well. Add $11 \mu \mathrm{l}$ of molecular grade $\mathrm{H}_{2} \mathrm{O}$ to each well. Remove reaction plate from the IMAG separation device and mix well by gentle vortexing. Place the reaction plate onto the IMAG separation device for 1 minute to separate the beads from the solution. Transfer $10 \mu \mathrm{l}$ of the cleaned up PCR product to a sterile 96 well plate for the next PCR step.

PCR 2: Reverse Tagging Step using the cleaned product from PCR 1 using equimolar mixture of the reverse frame-shift (FS) primers $808 R \_f 1,808 R \_f 2,808 R \_f 3,808 R \_4$, 808R_f5, 808R_f6). Primers are combined into a working stock of $0.5 \mu \mathrm{M}$. Perform 1 cycle PCR using $10 \mu \mathrm{l}$ of product from PCR 1. Prepare a mastermix solution $[5 \mu \mathrm{l} 5 \mathrm{x}$ Phusion Hifi Buffer, $0.5 \mu \mathrm{l}(10 \mathrm{mM}) \mathrm{dNTP}, 2 \mu \mathrm{l}(0.5 \mu \mathrm{M}$, Reverse_MT_tag Primer mix); $0.25 \mu \mathrm{l}$ Phusion HS II polymerase and $7.25 \mu$ DEPC water] and amplify using the following condition: $98^{\circ} \mathrm{C}$ for $60 \mathrm{sec}(\mathrm{x} 1) \rightarrow 98^{\circ} \mathrm{C}$ for $10 \mathrm{sec}+50^{\circ} \mathrm{C}$ for $30 \mathrm{sec}+72^{\circ} \mathrm{C}$ for $60 \mathrm{sec}(1 \mathrm{cycle}) \rightarrow$ hold at $4^{\circ} \mathrm{C}$ for $\infty$. Next clean-up the PCR products from PCR 1 
using AxyPrep Mag PCR Clean-up kit as follows; vortex magnetic beads well before use to resuspend any magnetic beads that may have settled. Aliquot $15 \mu \mathrm{l}$ of Axygen beads to $10 \mu \mathrm{l}$ of PCR product into a sterile 96 well plate. Mix well by repeated pipetting and incubate at $R^{\circ} T$ for 5 min. Place the reaction plate onto the IMAG separation device and wait until the liquid goes clear. Remove the clear liquid from the plate and discard. Next add $180 \mu \mathrm{l}$ of $70 \% \mathrm{EtOH}$ to each well of the reaction plate and incubate for $30 \mathrm{sec}$ at $\mathrm{R}^{\circ} \mathrm{T}$. Remove the $70 \% \mathrm{EtOH}$ from each well and discard. Repeat the previous step once. Air dry the beads at $\mathrm{R}^{\circ} \mathrm{T}$ for no more than $5 \mathrm{~min}$ and be careful not to over dry the magnetic beads as this will cause the beads to crack and lead to decreased elution efficiency. Ensure that all the ethanol has been removed from each well. Add $11 \mu \mathrm{l}$ of DECP water to each well. Remove reaction plate from the IMAG separation device and mix well by gentle vortexing. Place the reaction plate onto the IMAG separation device for 1 minute to separate the beads from the solution. Transfer $10 \mu l$ of the cleaned up PCR product to a sterile 96 well plate for the next PCR step.

PCR 3: Forward-Tagging Step using the cleaned product from PCR 2 using equimolar mixture of the forward frame-shift (FS) primers $515 \mathrm{~F} \_1$ 1, 515F_f2, 515F_f3, 515F_f4, $515 F_{-} f 5,515 F_{-}$f6). Primers are combined into a working stock of $0.5 \mu \mathrm{M}$. Perform 1 cycle PCR using $10 \mu \mathrm{l}$ of product from PCR 2. Prepare a mastermix solution $[5 \mu \mathrm{l} 5 \mathrm{x}$ Phusion Hifi Buffer, $0.5 \mu \mathrm{l}(10 \mathrm{mM}) \mathrm{dNTP}, 2 \mu \mathrm{l}(0.5 \mu \mathrm{M}$, Reverse_MT_tag Primer mix); $0.25 \mu$ l Phusion HS II polymerase and $7.25 \mu$ DEPC water] and amplify using the following condition: $98^{\circ} \mathrm{C}$ for $60 \mathrm{sec}(x 1) \rightarrow 98^{\circ} \mathrm{C}$ for $10 \mathrm{sec}+50^{\circ} \mathrm{C}$ for $30 \mathrm{sec}+72^{\circ} \mathrm{C}$ for $60 \mathrm{sec}(1 \mathrm{cycle}) \rightarrow$ hold at $4^{\circ} \mathrm{C}$ for $\infty$. Next clean-up the PCR products from PCR 3 using AxyPrep Mag PCR Clean-up kit as follows; vortex magnetic beads well before use to resuspend any magnetic beads that may have settled. Aliquot $17.5 \mu$ l of Axygen 
beads to $10 \mu \mathrm{l}$ of PCR product into a sterile 96 well plate. Mix well and incubate at $R^{\circ} T$ for $5 \mathrm{~min}$. Next place the reaction plate onto the IMAG separation device and wait until the liquid goes clear. Remove the clear liquid from the plate and discard. Add $180 \mu$ of $70 \% \mathrm{EtOH}$ to each well of the reaction plate and incubate for $30 \mathrm{sec}$ at $\mathrm{R}^{\circ} \mathrm{T}$. Remove the $70 \% \mathrm{EtOH}$ from each well and discard. Repeat previous step once. Air dry the beads at $R^{\circ} T$ for no more than 5 min, be careful not to over dry the magnetic beads as this will cause the beads to crack and lead to decreased elution efficiency. Ensure that all the ethanol has been removed from each well. Add $16 \mu$ l of DEPC water to each well and remove the reaction plate from the IMAG separation device and mix well to resuspend the magnetic beads. Next place the reaction plate onto the IMAG separation device for 1 minute to separate the beads from the solution. Transfer $15 \mu \mathrm{l}$ of the cleaned up PCR product to a sterile 96 well plate for the next PCR step.

PCR 4: Nextera-Adapter/Indexing Amplification step by performing a 34 cycle PCR, targeting the V4 region of the $16 \mathrm{~S}$ rRNA marker gene, using $15 \mu$ l of the cleaned reverse and forward tagged product from step PCR 3. Each reaction will have the same forward primers and a unique reverse primer which acts as the index (barcode) for each sample. The forward and reverse primers are typically diluted to a working stock of $5 \mu \mathrm{M}$ and can be added separately to each reaction (the forward primer is universal and could be added to any master-mixes instead), or the forward primer can be added to each reverse primer in a working stock in a plate for further use. Prepare a mastermix solution [10 $\mu \mathrm{l} 5 \mathrm{x}$ Phusion Hifi Buffer, $1 \mu \mathrm{l}(10 \mathrm{mM}) \mathrm{dNTP}, 2.5 \mu \mathrm{l}$ forward primer (SEQ_V4_F; AATGATACGGCGACCACCGAGATCTACACGCCTCCCTCGCGCCATCAGAGATG TG); $\quad 2.5 \mu \mathrm{l} \quad$ reverse primer $\quad$ (INDEX_R_bc1 to bc96; 
DEPC water] and amplify using the following condition: $98^{\circ} \mathrm{C}$ for $30 \sec (x 1) \rightarrow 98^{\circ} \mathrm{C}$ for $10 \mathrm{sec}+63^{\circ} \mathrm{C}$ for $30 \mathrm{sec}+72^{\circ} \mathrm{C}$ for $30 \mathrm{sec}(34$ cycle $) \rightarrow$ hold at $4^{\circ} \mathrm{C}$ for $\infty$. Next run $5 \mu \mathrm{l}$ of each reaction on a $1 \%$ agarose gel to visually confirm presence of products ( 453bp). Clean the PCR products from step PCR 4 with AxyPrep Mag PCR Cleanup kit as follows; vortex magnetic beads well before use to resuspend any magnetic beads that may have settled. Aliquot $35 \mu$ l of Axygen beads and the entire PCR product into a sterile 96 well plate and $\operatorname{mix}$ well and incubate at $\mathrm{R}^{\circ} \mathrm{T}$ for $5 \mathrm{~min}$. Next place the reaction plate onto the IMAG separation device and wait until the liquid goes clear. Remove the clear liquid from the plate and discard. Add $180 \mu \mathrm{l}$ of $70 \% \mathrm{EtOH}$ to each well of the reaction plate and incubate for $30 \mathrm{sec}$ at $\mathrm{R}^{\circ} \mathrm{T}$. Remove the $70 \% \mathrm{EtOH}$ from each well and discard. Repeat the previous step once. Air dry the beads at $\mathrm{R}^{\circ} \mathrm{T}$ for no more than 5 min, avoiding to not over drying the magnetic beads as this will cause the beads to crack and lead to decreased elution efficiency. Next add $50 \mu$ l of DEPC water to each well and remove reaction plate from the IMAG separation device and mix well. Place the reaction plate back onto the IMAG separation device for 1 minute to separate the beads from the solution. Transfer all of the cleaned up PCR product to a sterile 96 well plate. Next quantify products using Quant-iT ${ }^{\mathrm{TM}}$ PicoGreen ${ }^{\circledR}$ dsDNA Assay kit (Life Technologies, UK) in a 96 well plate using $2 \mu$ l of cleaned product. Pool equimolar amounts from each sample adding no more than $20 \mu \mathrm{l}$ of each reaction to the final pool. Typically, only reactions that failed will need to be added at this volume (the pool will not be equimolar for them). Gel purify the pool by running it on a $1 \%$ agarose gel and gel extracting the correct size band ( 453bp) using the QIAEX II kit (Qiagen ,UK) according to manufactures instructions, removing as much of the excess agarose gel 

16S rRNA marker-gene sequencing.

\section{Culture-independent analysis}

639 Samples were joined together and de-multiplexed according to unique barcode sequences using QIIME 1.9.1 [30] pipeline. PhiX internal sequencing control was removed by aligning all sequences against the PhiX genome [31] using the bbduk.sh shell script from the BBTools package (available at https://jgi.doe.gov/data-and-tools/bbtools) where unaligned reads were retained. Sequences were clustered into their representative Operational taxonomic units (OTUs) at $97 \%$ sequence identity using the UCLUST algorithm [32] in a de novo reference style. A representative sequence from each OTU was chosen based upon abundance within that OTU and taxonomy was assigned using the RDP naïve Bayesian classifier[33] against the QIIME compatible Greengenes 13.8 database [34, 35]. The resulting OTU table (.biom) was converted to a tab-spaced text file to assess the prevalence of OTUs within sputum samples $(n=28)$, positive- $(n=4)$ and negative-controls $(n=4)$, which were included throughout both DNA extraction and library preparation procedures. We compared OTUs occurring in the background of the negative controls to those observed in the clinical samples and subsequently filtered any OTUs that were considered to be contaminants from the dataset prior to further analysis. A number of OTUs were detected in the background of the negative controls; with OTUs accounting for over $90 \%$ (OTUs $>0.5 \%$ ) of reads in the four negative controls displayed a low contribution in the clinical samples accounting for $0-0.008 \%$ of the total read number. Within the negative controls the most abundant OTUs belonged to taxa such as members of family Comamonadaceae Unclassified, family Oxalobacteraceae Unclassified, family Methylophilaceae Unclassified, Dechloromonas spp., Ralstonia spp., Sediminibacterium spp., family Bradyrhizobiaceae Unclassified, order Elusimicrobiales Unclassified and family Xanthomonadaceae Unclassified. Conversely, the main taxa in clinical samples belonged to members most often associated microbiota observed in the airways of 
PWCF, such as Pseudomonas spp., Streptococcus spp., Staphylococcus spp., Haemophilus spp., Porphyromonas spp., Prevotella spp. and Fusobacterium spp. Those accounted for over $90 \%$ of total read number within clinical samples (range $0.5-58 \%$ ) compared to $0.5 \%$ (range $0-0.4 \%)$ in the background of the negative-controls. Therefore, taxa that were most common in the clinical samples were retained for analysis as their presence in the clinical samples was not estimated to be significantly affected by background contamination. Furthermore, OTUs representing potential human sequences, Archaea, Cyanobacteria and unassigned OTUs were filtered out and treated as contaminating sequences prior to downstream analysis. The full list of the unrarefied count data for clinical samples, positive- and negative-controls is shown in Table S4.

672

\section{Statistical analysis and ecological community measurements}

A single $\mathrm{R}$ object was created from the .biom formatted OTU table, containing representative sequences and associated clinical metadata using phyloseq [36] for subsequent analysis in $R$ (ver. 3.5.2). Calculations of ecological indices was performed using PAST3 (https://folk.uio.no/ohammer/past/). All statistical analysis was performed in $\mathrm{R}$ using the packages phyloseq (ver. 1.26.1), vegan (ver. 2.5-4) [37], dplyr (ver. 0.8.4) [38], ggplot2 (ver. 3.3.0) [39], Hmisc (ver. 4.2-0) [40], reshape (ver. 0.8.8) [41] and rmcorr (ver. 0.3.0) [42]. Furthermore, OTUs representing potential human sequences, Archaea, Cyanobacteria and unassigned OTUs were filtered out and treated as contaminating sequences prior to downstream analysis and all samples were randomly sub-sampled to 58,391 reads for diversity and dissimilarity calculations.

Alpha-diversity (within group) indices, such as community richness (S), diversity (ShannonWiener index; $\left.H^{\prime}\right)$, evenness $\left(e^{H / S}\right)$ and dominance (D) were compared between groups using the Wilcoxon-Rank sum test (2 groups). Beta-diversity (between groups) was assessed using distance-based metrics (Euclidean-distance) on centered log-ratio (CLR) transformed count 

first two components. Differences between groups were evaluated by multivariatepermutational analysis (PERMANOVA). Correlation between variables was made by calculating the spearman correlation coefficient, both before and after adjusting for repeated measures for PRE- and POST-ivacaftor samples. Where appropriate, p-values were adjusted for multiple testing using the Benjamini-Hochberg $(\mathrm{BH})$ method for false-discovery rate.

[1] Ramsey BW, Davies J, McElvaney NG, Tullis E, Bell SC, Drevinek P, et al. A CFTR potentiator in patients with cystic fibrosis and the G551D mutation. N Engl J Med. 2011;365:1663-72.

[2] Davies J, Sheridan H, Bell N, Cunningham S, Davis SD, Elborn JS, et al. Assessment of clinical response to ivacaftor with lung clearance index in cystic fibrosis patients with a G551D-CFTR mutation and preserved spirometry: a randomised controlled trial. Lancet Respir Med. 2013;1:630-8.

[3] Cutting GR. Cystic fibrosis genetics: from molecular understanding to clinical application. Nat Rev Genet. 2015;16:45-56. Epub 2014 Nov 18 doi:10.1038/nrg3849.

702 Cystic Fibrosis: Sustained Improvements in Ultra-Low-Dose Chest CT Scores After CFTR Modulation With Ivacaftor. Chest. 2018;153:395-403.

[5] Quinn RA, Lim YW, Maughan H, Conrad D, Rohwer F, Whiteson KL. Biogeochemical Forces Shape the Composition and Physiology of Polymicrobial Communities in the Cystic Fibrosis Lung. mBio. 2014;5:. doi:10.1128/mBio.00956-13.

[6] Rowe SM, Heltshe SL, Gonska T, Donaldson SH, Borowitz D, Gelfond D, et al. Clinical Mechanism of the Cystic Fibrosis Transmembrane Conductance Regulator Potentiator Ivacaftor in G551D-mediated Cystic Fibrosis. Am J Respir Crit Care Med. 2014;190:175-84. Epub 2014 Jul 15 doi:10.1164/rccm.201404-07030C.

[7] Bernarde C, Keravec M, Mounier J, Gouriou S, Rault G, Ferec C, et al. Impact of the CFTR-potentiator ivacaftor on airway microbiota in cystic fibrosis patients carrying a G551D mutation. PLoS One. 2015;10:e0124124.

[8] Reznikov LR, Abou Alaiwa MH, Dohrn CL, Gansemer ND, Diekema DJ, Stoltz DA, et al. Antibacterial properties of the CFTR potentiator ivacaftor. J Cyst Fibros. 2014;13:515-9.

[9] Payne JE, Dubois AV, Ingram RJ, Weldon S, Taggart CC, Elborn JS, et al. Activity of innate antimicrobial peptides and ivacaftor against clinical cystic fibrosis respiratory pathogens. Int J Antimicrob Agents. 2017;50:427-35.

[10] Einarsson GG, Comer DM, Mcllreavey L, Parkhill J, Ennis M, Tunney MM, et al. Community dynamics and the lower airway microbiota in stable chronic obstructive pulmonary disease, smokers and healthy non-smokers. Thorax. 2016;71:795-803.

[11] Sherrard LJ, Einarsson GG, Johnston E, O'Neill K, Mcllreavey L, McGrath SJ, et al. Assessment of stability and fluctuations of cultured lower airway bacterial communities in people with cystic fibrosis. J Cyst Fibros. 2019;18:808-16.

[12] Nadkarni MA, Martin FE, Jacques NA, Hunter N. Determination of bacterial load by real-time PCR using a broad-range (universal) probe and primers set. Microbiology. 2002;148:257-66.

[13] Deschaght P, Schelstraete P, Lopes dos Santos Santiago G, Van Simaey L, Haerynck F, Van daele $\mathrm{S}$, et al. Comparison of culture and qPCR for the detection of Pseudomonas aeruginosa in not chronically infected cystic fibrosis patients. BMC Microbiol. 2010;10:245.:10.1186/471-2180-10-245. 
[14] Lundberg DS, Yourstone S, Mieczkowski P, Jones CD, Dangl JL. Practical innovations for highthroughput amplicon sequencing. Nat Methods. 2013;10:999-1002.

[15] Caporaso JG, Kuczynski J, Stombaugh J, Bittinger K, Bushman FD, Costello EK, et al. QIIME allows analysis of high-throughput community sequencing data. Nat Methods. 2010;7:335-6.

[16] Muhlebach MS, Hatch JE, Einarsson GG, McGrath SJ, Gilipin DF, Lavelle G, et al. Anaerobic bacteria cultured from CF airways correlate to milder disease-a multisite study. Eur Respir J. 2018;52:. Epub 2018 Jul 11 doi:10.1183/13993003.00242-2018. [17] Heltshe SL, Mayer-Hamblett N, Burns JL, Khan U, Baines A, Ramsey BW, et al. Pseudomonas aeruginosa in cystic fibrosis patients with G551D-CFTR treated with ivacaftor. Clin Infect Dis. 2015;60:703-12.

[18] Hisert KB, Heltshe SL, Pope C, Jorth P, Wu X, Edwards RM, et al. Restoring Cystic Fibrosis Transmembrane Conductance Regulator Function Reduces Airway Bacteria and Inflammation in People with Cystic Fibrosis and Chronic Lung Infections. Am J Respir Crit Care Med. 2017;195:1617-28. [19] Peleg AY, Choo JM, Langan KM, Edgeworth D, Keating D, Wilson J, et al. Antibiotic exposure and interpersonal variance mask the effect of ivacaftor on respiratory microbiota composition. J Cyst Fibros. 2018;17:50-6. doi: 10.1016/j.jcf.2017.08.002. Epub Oct 15.

[20] Tang XX, Ostedgaard LS, Hoegger MJ, Moninger TO, Karp PH, McMenimen JD, et al. Acidic pH increases airway surface liquid viscosity in cystic fibrosis. J Clin Invest. 2016;126:879-91. doi: 10.1172/JCl83922. Epub 2016 Jan 25.

[21] Berkebile AR, McCray PB, Jr. Effects of airway surface liquid pH on host defense in cystic fibrosis. Int J Biochem Cell Biol. 2014;52:124-9.:10.1016/j.biocel.2014.02.009. Epub Feb 19.

[22] Pezzulo AA, Tang XX, Hoegger MJ, Alaiwa MHA, Ramachandran S, Moninger TO, et al. Reduced airway surface $\mathrm{pH}$ impairs bacterial killing in the porcine cystic fibrosis lung. Nature. 2012;487:109.

[23] Shah VS, Meyerholz DK, Tang XX, Reznikov L, Alaiwa MA, Ernst SE, et al. Airway acidification initiates host defense abnormalities in cystic fibrosis mice. Science. 2016;351:503-7.

757 [24] Lane D. 16S/23S rRNA sequencing. Nucleic acid techniques in bacterial systematics (Stackebrandt 758 E \& Goodfellow M, eds). Wiley, New York; 1991.

759 [25] Muyzer G, De Waal EC, Uitterlinden AG. Profiling of complex microbial populations by denaturing gradient gel electrophoresis analysis of polymerase chain reaction-amplified genes coding for $16 \mathrm{~S}$ rRNA. Appl Environ Microbiol. 1993;59:695-700.

[26] Edgar RC. MUSCLE: multiple sequence alignment with high accuracy and high throughput. Nucleic acids research. 2004;32:1792-7.

[27] Altschul SF, Madden TL, Schäffer AA, Zhang J, Zhang Z, Miller W, et al. Gapped BLAST and PSIBLAST: a new generation of protein database search programs. Nucleic acids research. 1997;25:3389402.

[28] Cole JR, Wang Q, Cardenas E, Fish J, Chai B, Farris RJ, et al. The Ribosomal Database Project: improved alignments and new tools for rRNA analysis. Nucleic acids research. 2009;37:D141-D5.

[29] Lundberg DS, Yourstone S, Mieczkowski P, Jones CD, Dangl JL. Practical innovations for highthroughput amplicon sequencing. Nature methods. 2013;10:999-1002.

[30] Caporaso JG, Kuczynski J, Stombaugh J, Bittinger K, Bushman FD, Costello EK, et al. QIIME allows analysis of high-throughput community sequencing data. Nature methods. 2010;7:335-6.

[31] Air GM, Els MC, Brown LE, Laver WG, Webster RG. Location of antigenic sites on the threedimensional structure of the influenza N2 virus neuraminidase. Virology. 1985;145:237-48.

[32] Edgar RC. Search and clustering orders of magnitude faster than BLAST. Bioinformatics. 2010;26:2460-1.

[33] Wang Q, Garrity GM, Tiedje JM, Cole JR. Naive Bayesian classifier for rapid assignment of rRNA sequences into the new bacterial taxonomy. Appl Environ Microbiol. 2007;73:5261-7.

[34] DeSantis TZ, Hugenholtz P, Larsen N, Rojas M, Brodie EL, Keller K, et al. Greengenes, a chimerachecked 16S rRNA gene database and workbench compatible with ARB. Appl Environ Microbiol. 2006;72:5069-72. 
[35] McDonald D, Price MN, Goodrich J, Nawrocki EP, DeSantis TZ, Probst A, et al. An improved Greengenes taxonomy with explicit ranks for ecological and evolutionary analyses of bacteria and archaea. The ISME journal. 2012;6:610.

[36] McMurdie PJ, Holmes S. phyloseq: an R package for reproducible interactive analysis and graphics of microbiome census data. Plos One. 2013;8:e61217. [37] Jari Oksanen FGB, Michael Friendly, Roeland Kindt, Pierre Legendre, Dan McGlinn, Peter R. Minchin, R. B. O'Hara, Gavin L. Simpson, Peter Solymos, M. Henry H. Stevens, Eduard Szoecs, Helene Wagner. vegan: Community Ecology Package. $\mathrm{R}$ package version 2.5-4. https://CRANRprojectorg/package=vegan. 2019.

[38] Hadley Wickham RF, Lionel Henry, Kirill Müller dplyr: A Grammar of Data Manipulation. R package version 0801. 2019; https://CRAN.R-project.org/package=dplyr. [40] Harrell Jr FE, Harrell Jr MFE. Package 'Hmisc'. CRAN2018. 2015:235-6. 

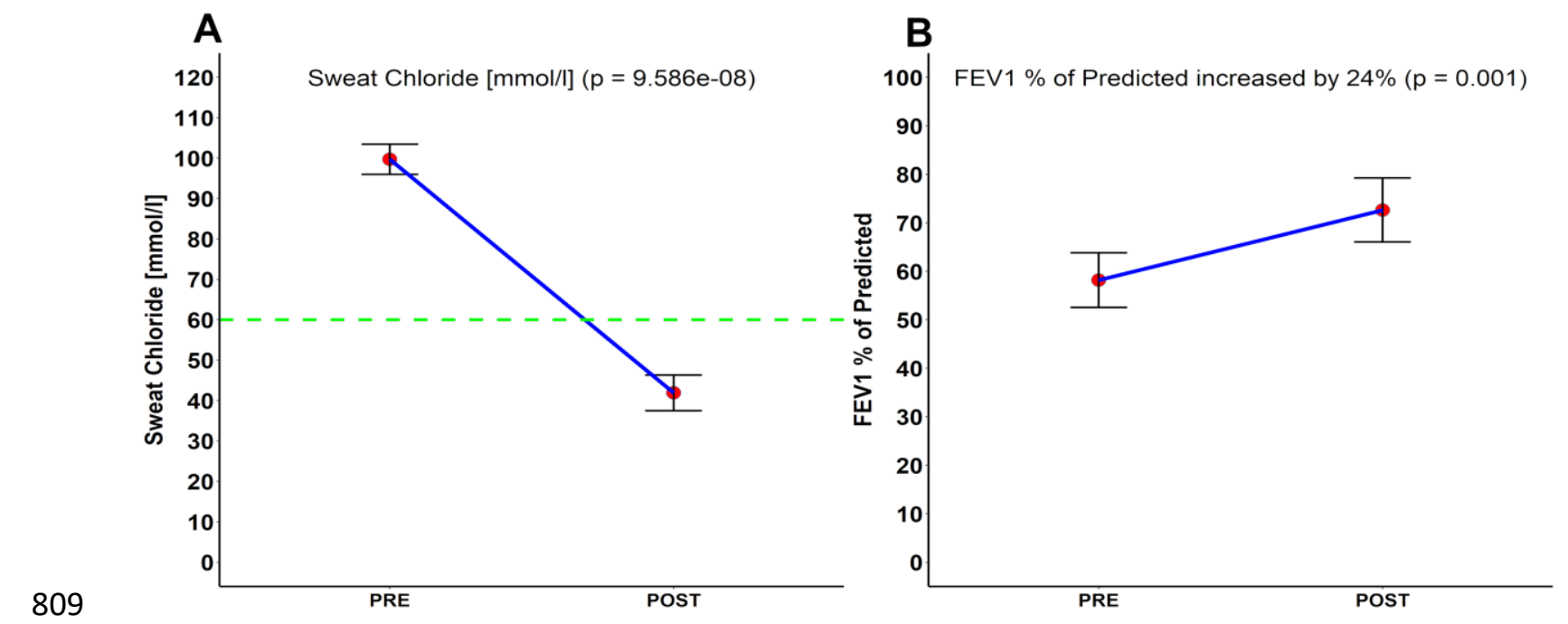

810 Fig S1. Changes in (A) sweat chloride levels and (B) lung function following ivacaftor 811 treatment. Red dots demonstrate mean levels and whiskers standard deviation around the 812 mean. The green dotted line displays the threshold of $60 \mathrm{mmol} / \mathrm{l}$ which is indicative of cystic 813 fibrosis diagnosis. Wilcoxon signed-rank test, $\mathrm{P}<0.05$ denotes statistical significance. 


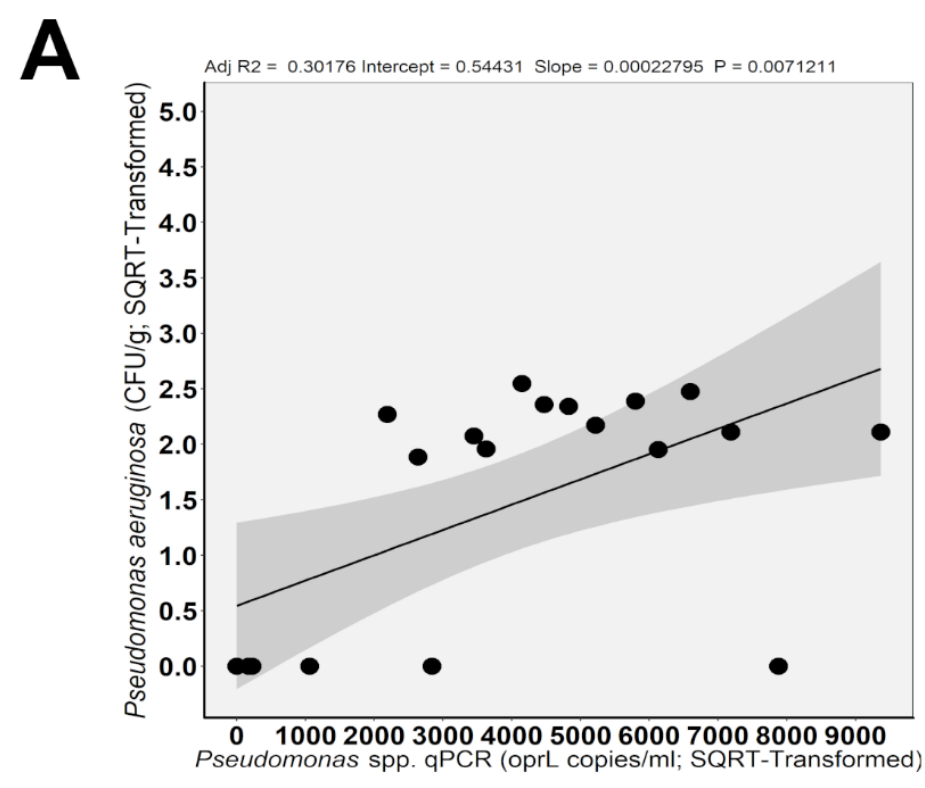

B

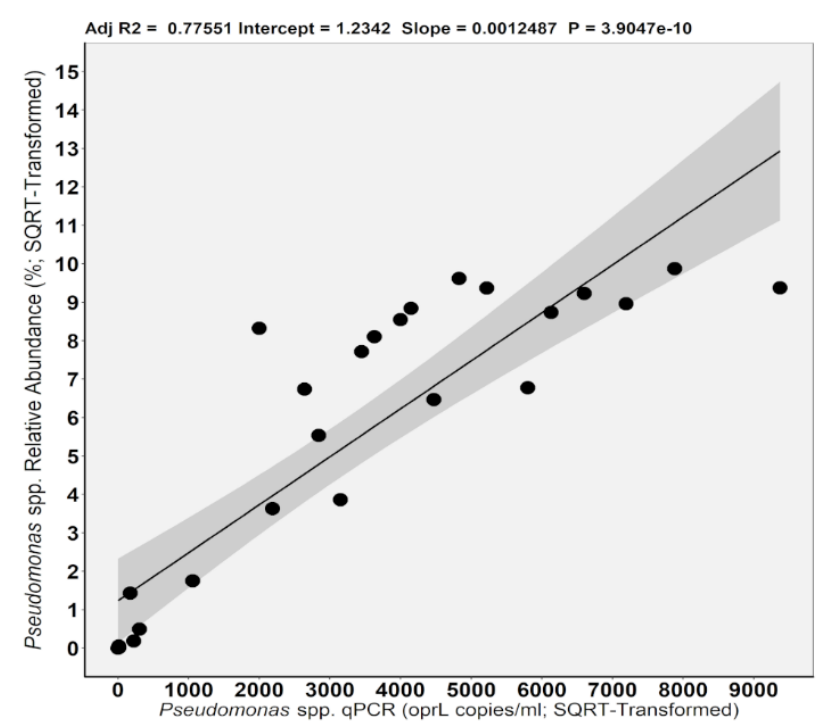

817 Fig S2. Pearson's correlation coefficient demonstrating the relationship between $(A)$ the total 818 viable counts (CFU/g sputum) of Pseudomonas aeruginosa (from culture-dependent analysis) 819 with $P$. aeruginosa oph copy number (copies $/ \mathrm{ml}$ ) as quantified by qPCR. Pearson's correlation coefficient $r=0.556\left(R^{2}=0.301 ; p=0.007\right)$ and $(B)$ between the relative abundance (\%) of Pseudomonas spp. (from Illumina MiSeq 16S rRNA marker-gene sequencing) with $P$. aeruginosa oprL copy number (copies $/ \mathrm{ml}$ ) as quantified by qPCR. Pearson's correlation coefficient $r=0.885\left(R^{2}=0.776 ; p=3.91^{*} 10^{-10}\right)$. 

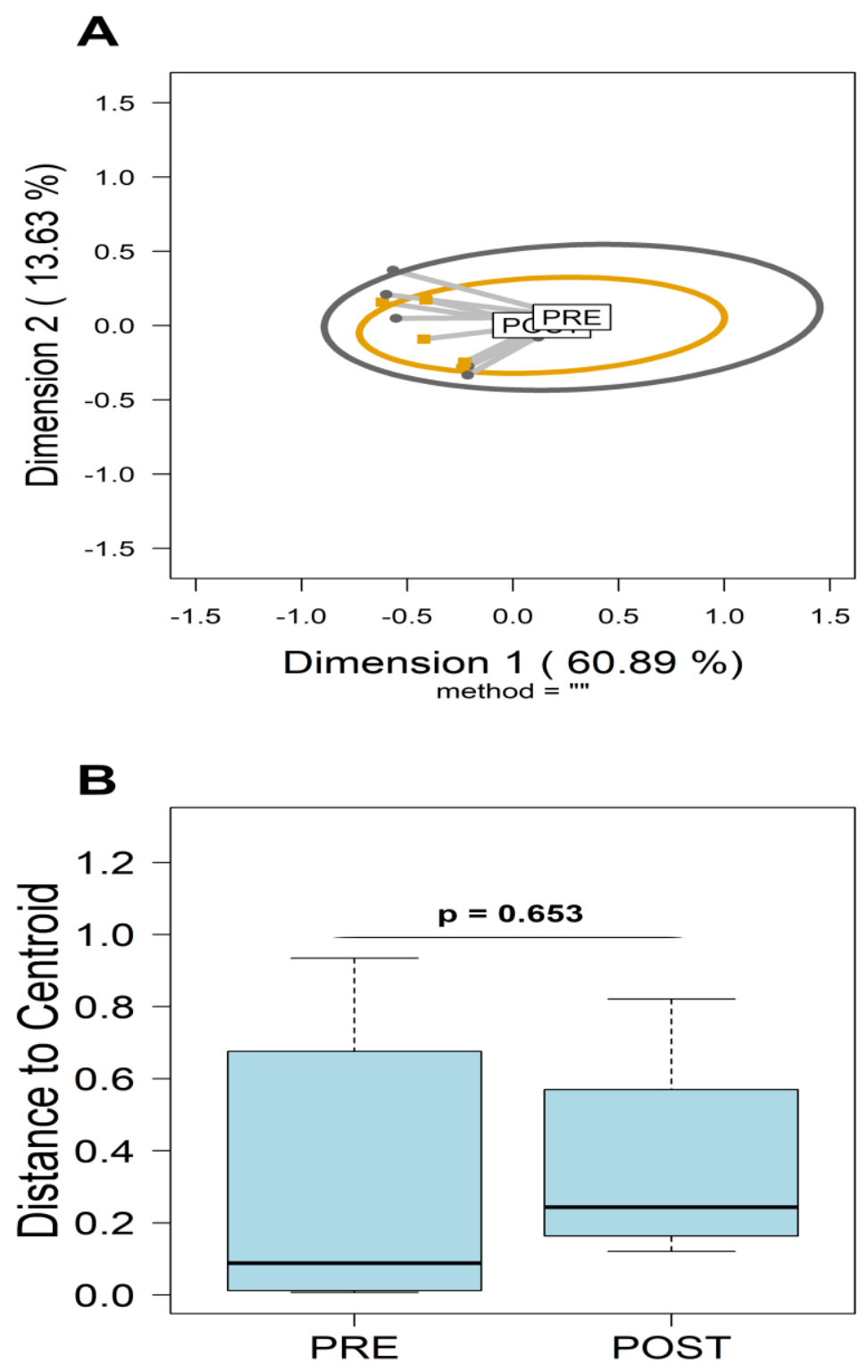

827 Fig S3. Differences in the compositional variance calculated using the Bray-Curtis distance 828 measure and the "betadisper" function from the vegan package (2.4-6) in R, followed by 829 significance testing using a permutation test. The permutation tests assess significant 830 differences of median distance to centroid. PRE- and POST-ivacaftor visits: (A) distances to 831 the centroids on the first two Principle Co-ordinates Analysis (PCoA) axes (90\% confidence 832 interval) and (B) distribution of variance. $P<0.05$ denotes statistical significance with 999 833 permutations. 
A

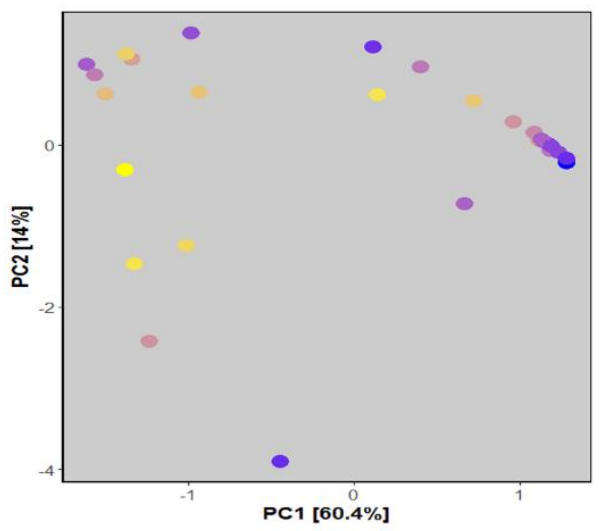

C

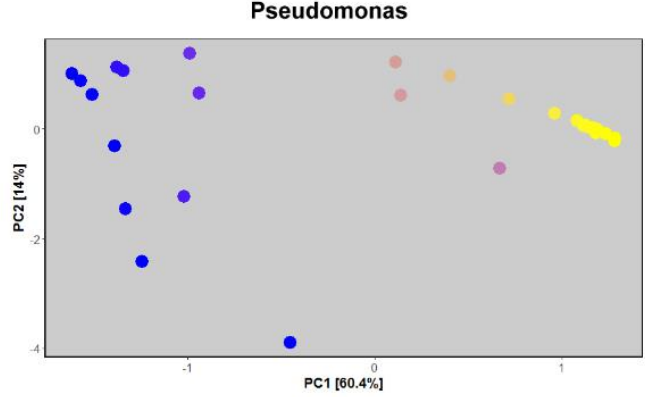

D

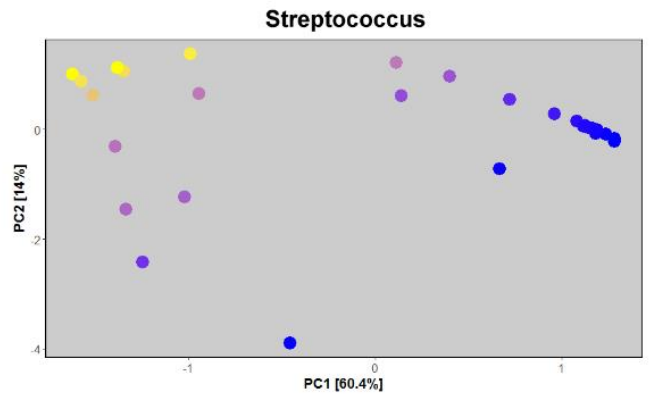

E

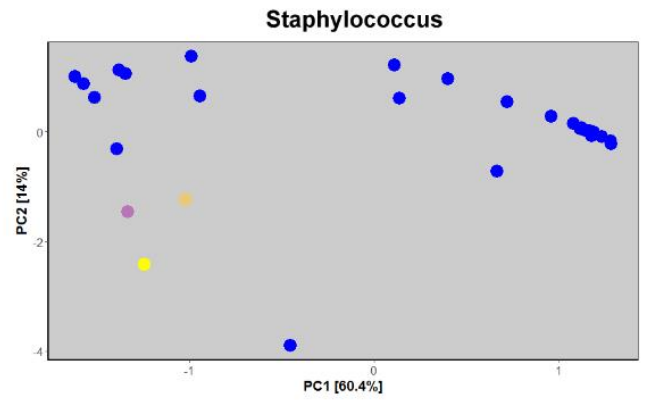

B

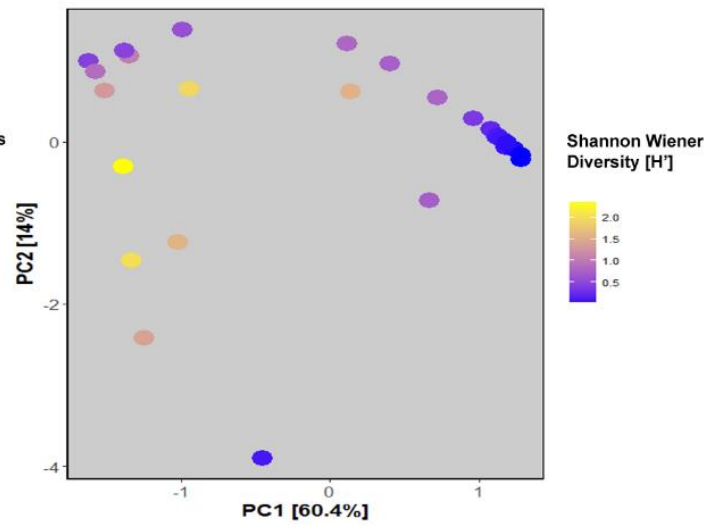

$\mathbf{F}$

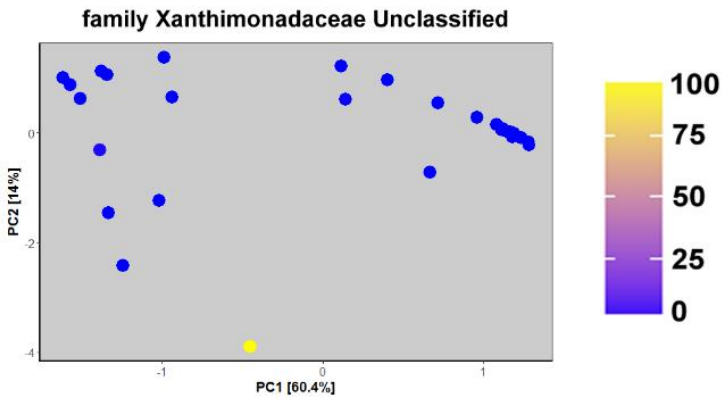

G

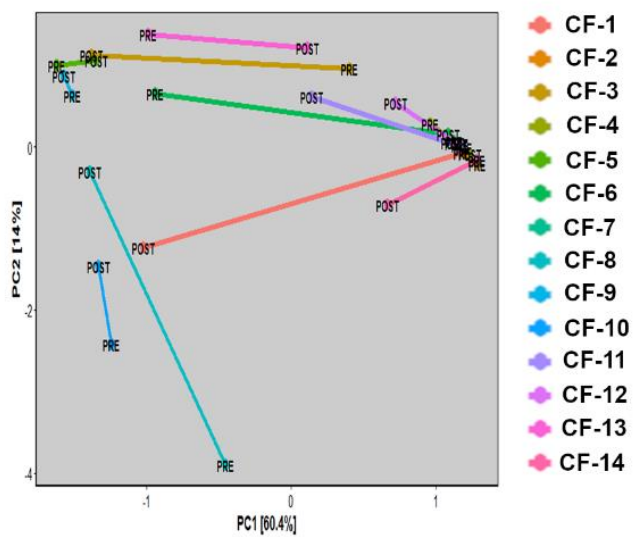

837 Fig S4. Principal Component Analysis (PCA) for the two main ecological community estimators: (A) Richness and (B) Shannon Wiener Diversity [H']. PCA analysis for the four main genera based on relative abundance (\% normalised counts): (C) Pseudomonas spp., (D) Streptococcus spp., (E) Staphylococcus spp. and (F) unclassified Xanthomonadaceae. (G) Direction of community changes from PRE- to POST-ivacaftor treatment. PCA axis 1 accounts for $60.4 \%$ of explained variation and the PCA axis 2 accounts for $14.0 \%$ of the variation explained. 

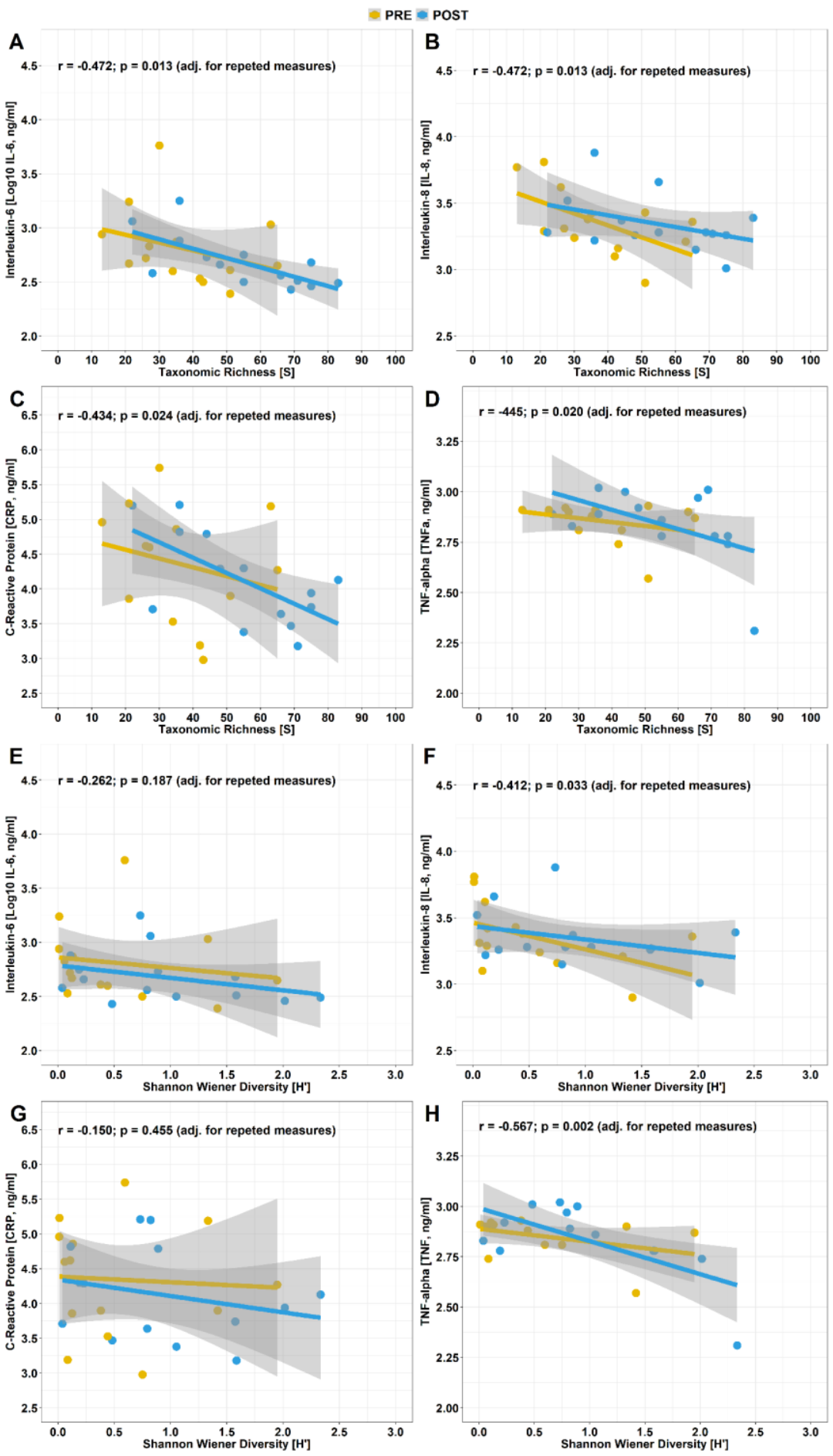
$\begin{array}{ll}847 & \text { Fig S5. Correlation ( } r \text { ) between taxonomic richness (A-D) and Shannon-Wiener diversity [H'] } \\ 848 & (\mathrm{E}-\mathrm{H}) \text { and markers of inflammation (IL-6, IL-8, C-Reactive Protein [CRP] and TNF- } \alpha \text { ) within }\end{array}$ the whole meta-community $(n=14)$. Correlation was adjusted for repeated measures $(r)$ taking into account the matched PRE- and POST-ivacaftor samples from the same individual using the rmcorr package (0.3.0) in R. Line indicates linear relationship between variables and the Spearman's correlation coefficient $(r) ; \mathrm{P}<0.05$ denotes statistical significance; shaded area denotes 95\% confidence limits. 
855 Table S2. Number of course of oral (PO) and intravenous (IV) antibiotics in the year before 856 and after ivacaftor.

857

\begin{tabular}{|c|c|c|}
\hline Patient & 1 year before & 1 year after \\
\hline CF-1 & $\begin{array}{c}2 \mathrm{PO} \\
0 \mathrm{IV}\end{array}$ & $\begin{array}{c}0 \text { PO } \\
0 \text { IV }\end{array}$ \\
\hline CF-2 & $\begin{array}{l}2 \text { IV } \\
6 \text { PO }\end{array}$ & $\begin{array}{c}0 \text { IV } \\
4 \text { PO }\end{array}$ \\
\hline CF-3 & $\begin{array}{c}0 \text { IV } \\
2 \text { PO }\end{array}$ & $\begin{array}{c}0 \text { IV } \\
0 \text { PO }\end{array}$ \\
\hline CF-4 & $\begin{array}{c}0 \text { IV } \\
2 \text { PO }\end{array}$ & $\begin{array}{c}0 \text { IV } \\
2 \text { PO }\end{array}$ \\
\hline CF-5 & $\begin{array}{c}0 \text { IV } \\
0 \text { PO }\end{array}$ & $\begin{array}{c}0 \text { IV } \\
1 \text { PO }\end{array}$ \\
\hline CF-6 & $\begin{array}{c}0 \text { IV } \\
2 \text { PO }\end{array}$ & $\begin{array}{c}0 \text { IV } \\
0 \text { PO }\end{array}$ \\
\hline CF-7 & $\begin{array}{c}5 \text { IV } \\
2 \text { PO }\end{array}$ & $\begin{array}{l}1 \text { IV } \\
2 \text { PO }\end{array}$ \\
\hline CF-8 & $\begin{array}{l}1 \text { IV } \\
0 \text { PO }\end{array}$ & $\begin{array}{l}0 \text { IV } \\
0 \text { PO }\end{array}$ \\
\hline CF-9 & $\begin{array}{c}0 \text { IV } \\
4 \text { PO }\end{array}$ & $\begin{array}{l}0 \text { IV } \\
0 \text { PO }\end{array}$ \\
\hline CF-10* & $\begin{array}{c}2 \text { IV } \\
1 \mathrm{PO}\end{array}$ & $\begin{array}{l}1 \text { IV } \\
2 \text { PO }\end{array}$ \\
\hline CF-11 & $\begin{array}{c}0 \text { IV } \\
2 \text { PO }\end{array}$ & $\begin{array}{c}0 \text { IV } \\
1 \text { PO }\end{array}$ \\
\hline CF-12 & $\begin{array}{c}1 \text { IV } \\
3 \text { PO }\end{array}$ & $\begin{array}{c}0 \text { IV } \\
0 \text { PO }\end{array}$ \\
\hline CF-13* & $\begin{array}{l}1 \mathrm{IV} \\
2 \mathrm{PO}\end{array}$ & $\begin{array}{l}2 \text { IV } \\
2 \text { PO }\end{array}$ \\
\hline CF-14 & $\begin{array}{l}1 \mathrm{IV} \\
2 \mathrm{PO}\end{array}$ & $\begin{array}{l}0 \text { IV } \\
0 \text { PO }\end{array}$ \\
\hline
\end{tabular}

858

859 *patients received antibiotics within 8 weeks of post ivacaftor sputum sample 